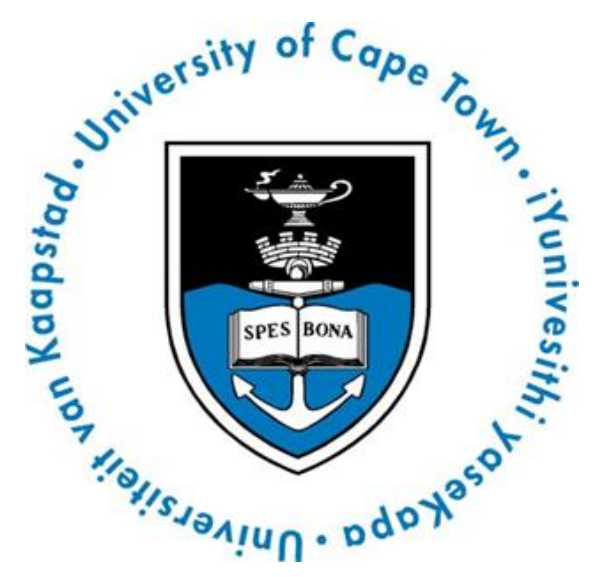

\title{
Prevalence of Shoulder Morbidity after Treatment for Breast Cancer in South Africa
}

\section{Nicole (Nicky) Kramer; KRMNIC003}

Submitted in partial fulfilment of the requirements for the degree MASTER OF PUBLIC HEALTH in the

\section{SCHOOL OF PUBLIC HEALTH AND FAMILY MEDICINE}

Supervisors:

$$
\text { Dr Delva Shamley }
$$

Clinical Research Centre (CRC), Faculty of Health Sciences, University of Cape Town

$$
\text { Mr Jordache (Jo) Ramjith }
$$

Division of Epidemiology \& Biostatistics, School of Public Health \& Family Medicine, University of Cape Town 
The copyright of this thesis vests in the author. No quotation from it or information derived from it is to be published without full acknowledgement of the source. The thesis is to be used for private study or noncommercial research purposes only.

Published by the University of Cape Town (UCT) in terms of the non-exclusive license granted to UCT by the author. 


\section{PART 0 PREAMble}




\section{Declaration}

I, Nicole Kramer (KRMNICO03), hereby declare that the work on which this dissertation is based is my original work (except where acknowledgements indicate otherwise) and that neither the whole work nor any part of it has been, is being, or is to be submitted for another degree in this or any other university.

I empower the university to reproduce for the purpose of research either the whole or any portion of the contents in any manner whatsoever.

Signed by candidate 


\section{Dedication}

I dedicate this thesis to my wonderful family, who have been part of this journey from the beginning. My mother, brother and grandmother have championed me through the challenges of completing this master's degree whilst working full-time, and have shown unwavering love and support.

I also dedicate this to my incredible boyfriend William, who has been a sounding board and constant source of encouragement whilst completing this thesis. 


\section{Abstract}

Breast cancer represents a significant public health burden globally, representing the most frequently diagnosed cancer among females. Within South Africa, female breast cancer accounts for $21.46 \%$ of all cancers. This has an impact on public health resources including hospital visits, treatment costs, and long-term morbidities. Upper limb pain and disability occur as a result of breast cancer treatments including surgery, radiotherapy and chemotherapy. This morbidity presents soon after treatment, persists into the long-term and may result in the need for post-treatment rehabilitation and an inability to return to work.

This dissertation addresses the prevalence and predictors of shoulder morbidity in women in Cape Town, South Africa, post- treatment for breast cancer.

Part $A$ is the study protocol, summarising the aims, methodology and ethical considerations for the study, including a rationale for its importance.

Part B is a structured literature review summarising pertinent research in the field, providing context for the dissertation and subsequent analysis.

Part $C$ is a journal-ready manuscript prepared for submission to the journal Acta Oncologica. This summarises the methodology, results and interpretation of the key findings of the analysis conducted.

The results showed that $75 \%$ of patients studied experienced some degree of pain or disability posttreatment for breast cancer. Multivariable ordinal logistic regression analysis identified race, side, axillary surgery, chemotherapy and age as significant predictors of pain, and chemotherapy a significant predictor of disability. This burden of disease many years after treatment represents a 
significant public health burden for South Africa. Using pre-identified clinical and demographic characteristics may guide in the development of survivorship programmes incorporating surveillance and treatment for these high-risk patients.

6 | P a g e 


\section{Acknowledgements}

I would like to thank my supervisors, Dr Delva Shamley and Mr Jo Ramjith for their excellent guidance and teaching throughout the process of completing this dissertation.

They provided constant support and encouragement, allowing me to complete this dissertation according to our pre-set timelines.

I am grateful to Dr Shamley for her topic suggestion and her invaluable insights into this field of research. I am grateful to Mr Ramjith for his statistical expertise and his willingness and patience to share it with me, and guide me in learning. 


\section{Table of Contents}

\section{PART A: RESEARCH PROTOCOL}

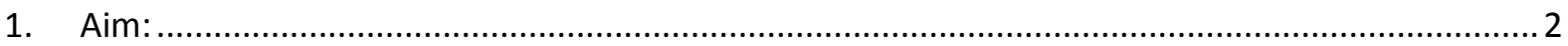

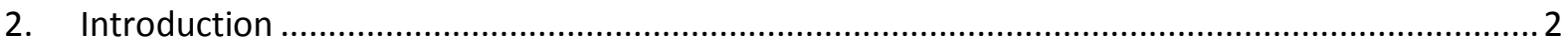

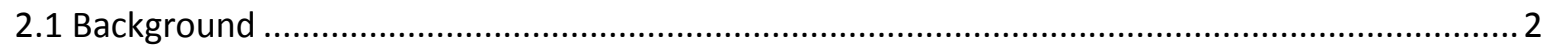

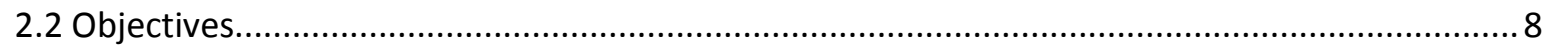

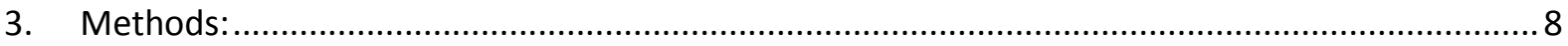

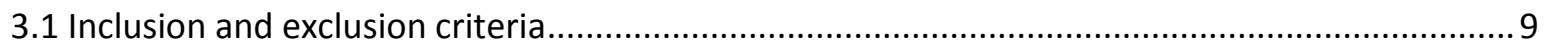

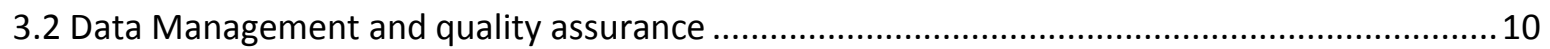

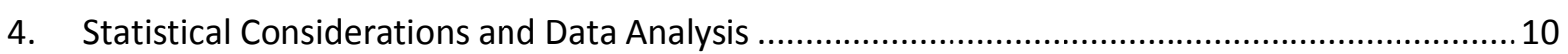

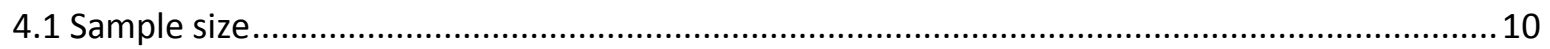

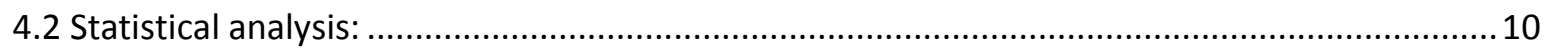

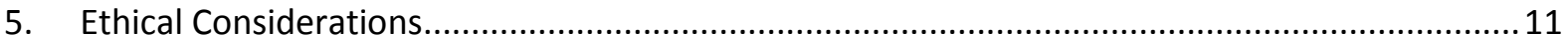

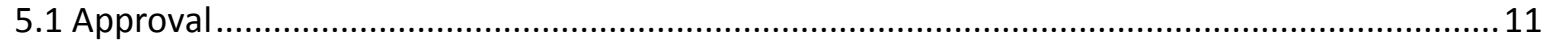

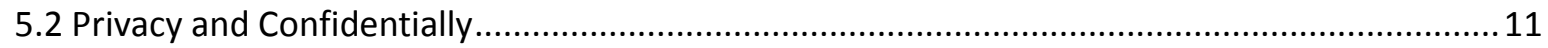

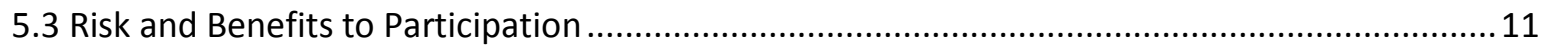

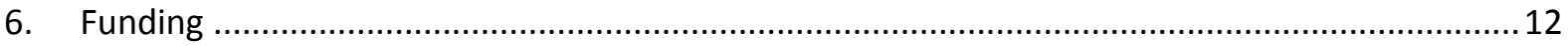

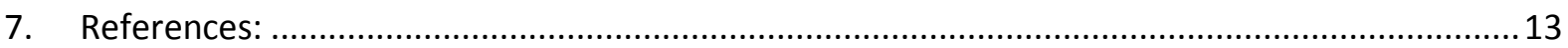

\section{PART B: LITERATURE REVIEW}

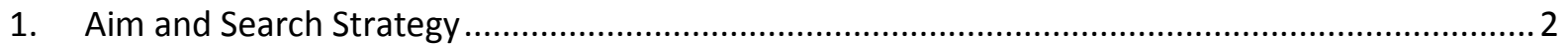

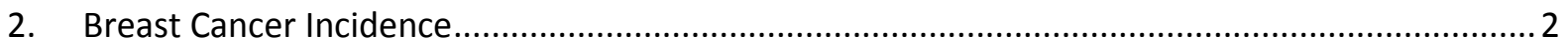

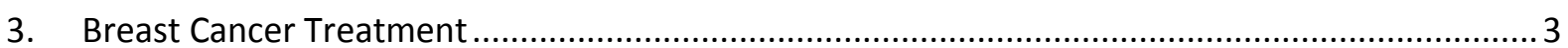

4. Breast Cancer Treatment Morbidity and Mortality ....................................................................... 4

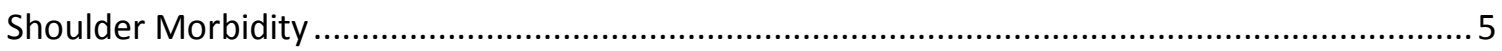

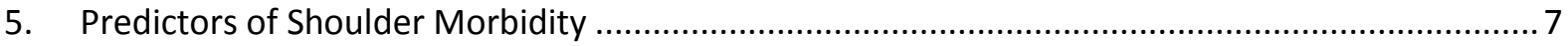

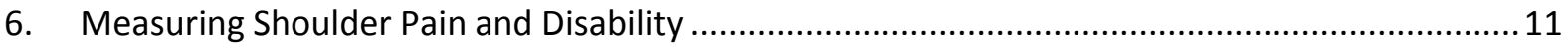

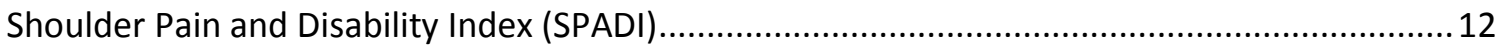

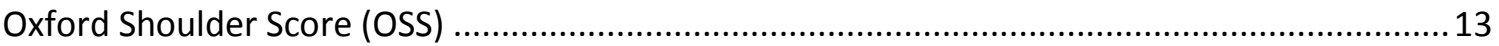




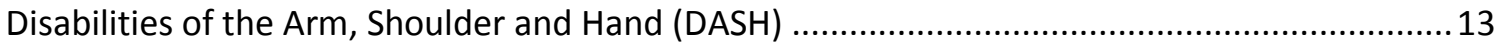

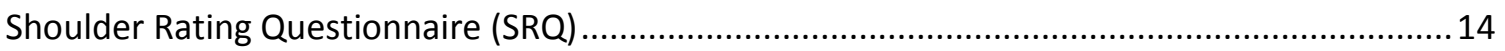

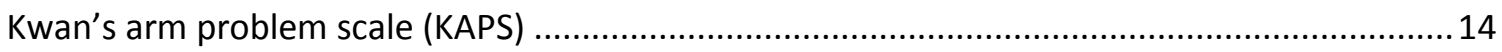

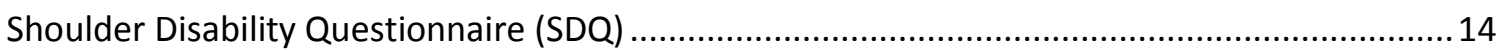

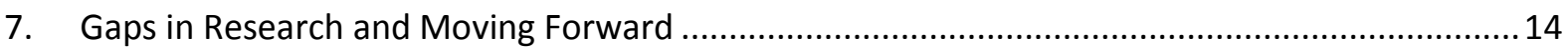

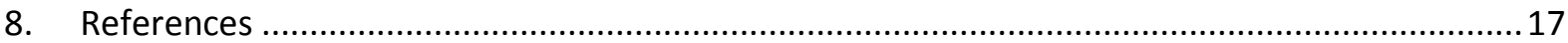

\section{PART C: JOURNAL READY MANUSCRIPT}

Introduction

\section{PART D: APPENDICES}

Appendix 1: SPADI Questionnaire

Appendix 2: Ethics Approval Letter

Appendix 3: Journal submission guidelines for Acta Oncologica 


\section{List of Tables}

\section{PART C: JOURNAL READY MANUSCRIPT}

Table 1. Participant Demographic and Clinical Characteristics (page 9)

Table 2. Summary of SPADI scores according to severity (page 11)

Table 3: Ordinal Logistic Regression for Pain Categories (page 14)

Table 4: Ordinal Logistic Regression for Disability Categories (page 15)

\section{List of Figures}

\section{PART C: JOURNAL READY MANUSCRIPT}

Figure 1: Stacked Bar Chart showing the association between Categories of Pain and Disability (page 12) 


\section{List of Abbreviations}

ADL: Activities of Daily Living

ALND: Axillary Lymph Node Dissection

BCS: Breast Cancer Survivors

BMI: Body Mass Index

DASH: Disabilities of the Arm, Shoulder and Hand

FACT-B: Functional Assessment of Cancer Therapy - Breast

HER2: Human Epidermal Growth Factor 2

HREC: Human Research Ethics Committee

KAPS: Kwan's Arm Problem Scale

KPS: Karnofsky Performance Status

MRM: Modified Radical Mastectomy

OSS: Oxford Shoulder Score

RCT: Randomized Controlled Trial

ROM: Range of Motion

SDQ: Shoulder Disability Questionnaire

SNB: Sentinel Node Biopsy

SPADI: Shoulder Pain and Disability Index

SRQ: Shoulder Rating Questionnaire

UCT: University of Cape Town

US: United States

VAS: Visual Analogue Scale

WHO AFRO: World Health Organization Africa Region

WLE: Wide Local Excision 


\section{PART A \\ ReSEARCH PROTOCOL}




\section{Aim}

To determine the prevalence of shoulder morbidity in women treated for breast cancer at a tertiary academic hospital in Cape Town, South Africa.

\section{Introduction}

\subsection{Background}

\section{Breast cancer incidence}

Globally, breast cancer is the most frequently diagnosed cancer and leading cause of cancer death among females in both low-to-middle income countries (LMICs) and high-income countries (HICs) (Jemal et al. 2011). Estimates from 2008 report that $23 \%$ of the total cancer cases and $14 \%$ of the cancer death is attributed to breast cancer with approximately $50 \%$ of the cases and $60 \%$ of the deaths occurring in LMICs (Jemal et al. 2011). Globally, the age-standardized rate of breast cancer per 100,000 is $27.3 \%$ for LMICs countries compared to $66.4 \%$ for HICs (Jemal et al. 2011). In LMICs, it is associated with a lower cumulative mortality risk (0-74 years) of $1.2 \%$ compared to $9 \%$ for all cancers (Jemal et al. 2011)

This disease represents a considerable public health burden in South Africa (Herbst 2016). Although rare in men, breast cancer accounts for $0.45 \%$ of all male cancers (National Health Laboratory Service 2011). Data from the South African National Cancer Registry reports an increased incidence of breast cancer for women in 2011 of 6849 per 100000 per year , compared to 6125 and 5280 per 100000 per year in 2010 and 2000, respectively (Herbst 2016; National Health Laboratory Service 2011). When breaking down the statistics, the incidence of 6849 represents $21.46 \%$ of all cancers in females, with 
a cumulative lifetime incidence risk (0-74 years) of 3.51\% and a lifetime risk of 1 in 29 females developing breast cancer (National Health Laboratory Service 2011).

More specifically, the greatest incidence of breast cancer in females occurs between the ages of 45 64 years, and can occur as young as between 10-14 years old and as old as 85 years (National Health Laboratory Service 2011). When broken down according to race, breast cancer accounts for $20.87 \%$ of cancers in Black African females, $35.44 \%$ in Asian females, $26.63 \%$ in mixed ancestry female, and 19.89\% in Caucasian females (National Health Laboratory Service 2011).

In high-income countries, mortality rates from breast cancer have declined over time, with a resultant improvement in survival rates from 10\% in 1970 to about 40\% for women treated after 1995 (Tosello et al. 2014). Recent data in 2012 from the International Cancer Research group, Globocan, estimate incidence, mortality and 5-year prevalence of breast cancer in women for the World Health Organization Africa Region (WHO AFRO) as $26.2 \%, 19.6 \%$ and $35.5 \%$, respectively (International Agency for Research on Cancer (IARC) n.d.) Within the South African Republic, estimates are similar to the WHO AFRO data with incidence, mortality and 5-year prevalence of $24.5 \%, 15.9 \%$ and $34.3 \%$, respectively (International Agency for Research on Cancer (IARC) n.d.). When breast cancer is diagnosed and treated early, cure is often possible (UpToDate n.d.). Where implemented, screening programmes, early diagnosis and new treatments have resulted in a decline in mortality (UpToDate n.d.). However, these remain challenges for LMICs such as South Africa, where many patients present with advanced disease and there is a lack of access to newest treatment options that may be available in HICs (Mutebi \& Edge 2014; Marcus et al. 2013).

The medical management of breast cancer includes surgery, radiation, chemotherapy, biological agents, endocrine (hormonal) therapy, and/or a combination of these (Tosello et al. 2014). There are several surgical options including radical mastectomy (removal of the breast, lymph nodes and 
adjacent muscular tissue), modified radical mastectomy (removal of entire breast including axillary lymph nodes but not the muscular tissue) and breast conserving surgery (BCT) (Cotlar et al. 2003). BCT or breast conservation is also known as wide local excision (WLE) or partial mastectomy, and may include a lumpectomy whereby only the tumour and a margin of breast around the tumour is removed (UpToDate n.d.). Breast cancer treatment may result in patients surviving long-term and many experience long-term side effects as a result of the different treatment modalities. Furthermore, many receive a combination of treatments and thus may develop multiple issues (Shamley 2015).

\section{Post-treatment Morbidity}

These side effects include decreased sexuality and fertility, cardiovascular disease secondary to treatment, decreased bone health, lymphoedema, increased risk of second primary malignancies, and thromboembolic risk (Bodai \& Tuso 2015). Additionally, bilateral upper limb pain and dysfunction is a common complication after treatment for breast cancer and can present immediately after treatment or up to six years later (Bodai \& Tuso 2015; Hidding et al. 2014; Shamley et al. 2012)

Shoulder morbidity comprises decreased shoulder complex mobility, pain and numbness, tightness, oedema, and weakness. This may also include emotional distress resulting in isolation and can affect activities of daily living (ADL) including the ability to return to work (Shamley 2015). Although the mechanism for this is poorly understood, altered musculo-skeletal function affects the ability to move and results in reduced range of motion (ROM) and chronic pain (Shamley et al. 2012; Shamley 2015).

Therefore, research now includes evaluation of mechanics and genomics in order to better understand the aetiology (Shamley 2015). Reduced ROM, pain and lymphoedema are the most commonly described shoulder morbidities (Hidding et al. 2014). A systematic review evaluating the impairment in functions and structures in the upper extremity and upper body found that in women who received 
curative treatment interventions, the most significant of these was with axillary lymph node dissection (ALND) (Hidding et al. 2014). Treatments evaluated included surgery (mastectomy, lumpectomy, ALND, sentinel node biopsy (SNB), and breast reconstruction), radiotherapy, chemotherapy and hormonal therapy and outcomes assessed were reduced ROM, reduced muscle strength, pain, lymphoedema and decreased degree of ADL (Hidding et al. 2014).

The incidence of reduced ROM varies according to study design and length of follow up, however, reduced ROM occurs between 1\%-67\% of patients (Hidding et al. 2014). Risk factors include greater number of lymph nodes removed, cording (palpable cords in the axillary region that develop as a side effect of surgery), mastectomy, stage II breast cancer, side of hand dominance, and increased BMI and age (Hidding et al. 2014; Bodai \& Tuso 2015). Age is also a contributory factor to limitation in ADL, as well as ALND, radiotherapy and the presence of other comorbidities (Hidding et al. 2014). Reduced ROM develops in the first month post-operatively and appears to decrease with time (Hidding et al. 2014).

Contrastingly, breast cancer-related lymphoedema seems to increase over time, with a higher incidence after one month. Lymphoedema is a chronic, incurable and debilitating side effect of breast cancer treatment and occurs in up to $34 \%$ of patients (Hidding et al. 2014). Risk factors for lymphoedema include ALND, radical mastectomy, radiotherapy and chemotherapy (Hidding et al. 2014).

Pain occurs between $8 \%-68 \%$ of patients and reduction in muscle strength between $17 \%-72 \%$ of patients, with evidence suggesting that pain and dysfunction may last as long as up to 6 years (Hidding et al. 2014). Movement patterns are different for left versus right-sided affected, with the left side affected associated with greater levels of pain and dysfunction (Shamley et al. 2012). Moreover, the addition of chemotherapy further contributes to the difference seen between the affected and 
unaffected sides (Shamley et al. 2012). Acute and chronic pain appear to have a different set of risk factors; anxiety for acute post-operative pain, and more invasive surgery (mastectomy as opposed to WLE), radiotherapy and acute post-operative pain for chronic post-operative pain (Shamley et al. 2009) (Shamley et al. 2012). Connective tissue changes such as scarring and cording are also known contributory factors to arm dysfunction and pain after treatment. (Hidding et al. 2014).

A way to quantify these adverse events is to use patient-reported outcomes, with the aid of a validated questionnaire in order to establish the presence of pain and disability. A self-reported outcome measure is considered preferable over the use of ascertaining ROM when evaluating treatment effectiveness for clinical and research use (Williams et al. 1995).

\section{Shoulder Morbidity Questionnaires}

There are several self-reported shoulder disability questionnaires, including the Disabilities of the Arm, Shoulder, and Hand (DASH), Shoulder Pain and Disability Index (SPADI), the American Shoulder and Elbow Surgeons (ASES) score, the Shoulder Rating Questionnaire (SRQ) and the Simple Shoulder Test (SST) (Roy et al. 2009). There is currently no gold standard for measuring shoulder pain and disability. SPADI is often a preferred questionnaire for assessing shoulder problems presenting in primary care due to its validity, responsiveness to change, and acceptability. However, the decision for which questionnaire to use will be guided by the type of study and the practical considerations required (Paul et al. 2004).

The Shoulder Pain and Disability Index (SPADI) questionnaire is a reliable and valid measure of pain and disability for shoulder dysfunction (Roy et al. 2009). The scale is a visual analogue scale (VAS) of 13 items ( 5 for pain and 8 for disability). Scores for pain range from a minimum of $0 \mathrm{~cm}$ to a maximum of $50 \mathrm{~cm}$ and for disability $0-80 \mathrm{~cm}$. Patients are asked to range their answers between 0 and 10 , with 
0 representing no symptoms of pain or disability and 10 representing the worst pain imaginable and a need for help due to disability (Shamley et al. 2009). The VAS has been shown to have high reliability and concurrent validity and takes on average 5-20 minutes to complete (Roy et al. 2009; Breckenridge \& McAuley 2011).

SPADI was used in this patient cohort due to its ability to evaluate shoulder function, specifically with regards to the functional movement at the level of the shoulder. SPADI is also short and easy for patients to complete (Paul et al. 2004).

The resultant limitation in ADL may present a large challenge in LMICs such as South Africa, where oftentimes women are required to work in order to support the household. If a women is unable to work due to side effects from breast cancer treatment, this may have an impact on the family in terms of poverty, lack of access to care and dependence on their partners for financial support (Mutebi \& Edge 2014). The lack of structured rehabilitation and survivorship programmes means that access to upper limb rehabilitation often only occurs when patients present with advanced conditions of the shoulder.

\section{Long term surveillance and survivorship}

Given the burden of morbidity associated with breast cancer treatment, there is a clear need for prospective surveillance programmes that can be integrated into survivorship programmes, particularly within South Africa and other low-middle income countries. The ability to identify those patients at risk of long-term morbidity reduces the need for intensive rehabilitation and associated costs, which are not routinely part of the standard cancer care pathway (Shamley 2015). 
Physiotherapy and exercise are able to resolve these problems (McNeely et al. 2010), however, there are insufficient resources to provide rehabilitation programmes for each cancer patient and therefore there is a need to identify and target resources, particularly in a country such as South Africa where resources are limited. Thus, there is a need for surveillance and early clinical identification (Hidding et al. 2014). In order to design and implement integrated care pathways and service provision of upper limb deterioration, we require key baseline data to understand those patients who may be at risk and therefore better inform the development of those programmes.

This study will aim to quantify the burden of shoulder morbidity in this selected population, and identify potential risk factors for the development of shoulder adverse effects.

\subsection{Objectives}

The primary objective of this study is to determine the prevalence of shoulder pain and disability of adult women attending their post-treatment annual follow up visit for unilateral breast carcinoma at a tertiary academic centre.

The secondary objective is to evaluate associations between shoulder morbidity and covariates such as treatment protocol or baseline demographics.

\section{Methods}

This study will use data already collected from a primary study of women attending their annual breast clinic follow-up visit who completed the SPADI questionnaire, and thus is a secondary data analysis. 
Ethical clearance for the primary study was granted by the University of Cape Town Human Research Ethics Committee (approval number: 312/2012).

Women attending their annual check-up at the breast clinic at Groote Schuur Hospital, Cape Town, South Africa, were approached to be included in the study. Patients were reviewed according to predetermined inclusion and exclusion criteria (see section 4.1), and upon informed consent, participants completed the SPADI questionnaire in the language of their choice. Those requiring assistance to complete the questionnaire were assisted by research staff fluent in the language of the participant. No attempt was made to influence the participant's score. Additional clinical and demographic data was collected such as age, treatment protocol, tumour grade and side and location of primary tumour.

This study will be a cross-sectional analysis of the prevalence of shoulder pain and dysfunction in this sample of women. This study will report on women attending a large, tertiary academic breast cancer clinic, and therefore may not be representative of the South African population in terms of racial groups, access and level of treatment relative to a primary or secondary care centre.

\subsection{Inclusion and exclusion criteria}

Inclusion criteria:

1. Women 18 years of age and older

2. One year post surgery for unilateral carcinoma of the breast

Exclusion criteria:

1. Reconstructive surgery 
2. Current or previous history of shoulder complex trauma, surgery, pathology or dysfunction

3. Current or previous history of cervical neuropathy

\subsection{Data Management and quality assurance}

Clinical and demographic data was collected from the participant's hospital file and entered onto a case report form (CRF). Responses to the SPADI questionnaire were self-reported by the participants, in addition to information related to highest education level achieved and description of job duties. All information was captured independently into a RedCap database and is stored securely with access-control. The database has been $100 \%$ quality controlled twice.

\section{Statistical Considerations and Data Analysis}

\subsection{Sample size}

This was a convenience sample of women attending annual follow up appointments at the breast clinic at Groote Schuur Hospital between 2015-2017. The SPADI questionnaire was completed by 350 participants. Not all participants' medical records provided the required demographic and clinical data.

\subsection{Statistical analysis}

The data will be exported from the database for analysis in STATA (College Station, Texas, USA). 
Prevalence will be determined using summary statistics. Regression analysis will be used for determining the association(s) between pain scores and covariates, such as baseline demographics, time since treatment, and treatment type. Potential confounders and interacting variables will be considered in the analysis. A p-value of $\leq 0.05$ will be considered statistically significant.

\section{Ethical Considerations}

\subsection{Approval}

This study is using existing data from an approved primary study. Ethical clearance for the primary study was granted by the University of Cape Town Human Research Ethics Committee (approval number: 312/2012).

\subsection{Privacy and Confidentially}

Informed consent was received for all participants prior to collection of data. Personal information was de-identified and each participant was assigned a study number.

\subsection{Risk and Benefits to Participation}

The primary study presented minimal risks to the participants as no intervention was performed. Participation in the study did not benefit the participant. The results from this analysis will be disseminated and therefore will hopefully lead to an awareness of the need for post-cancer surveillance programmes.

All participants who reported a mean pain and disability score above 6 were referred to a consultant for physiotherapy. 


\section{Funding}

The time required (and associated cost) for analysis and write-up will be self-funded by the masters student. Funding will be provided for publication via an NRF grant held by Dr Delva Shamley (RRR Grant 93541). 


\section{References:}

Anon, 2014. Race, Ethnicity and Language in South Africa | World Elections. Available at:

https://welections.wordpress.com/guide-to-the-2014-south-african-election/race-ethnicityand-language-in-south-africa/ [Accessed September 18, 2017].

Anon, The Disabilities of the Arm, Shoulder and Hand (DASH) Outcome Measure. Available at: http://www.dash.iwh.on.ca/about-dash [Accessed July 25, 2017].

Blinder, V.S. \& Griggs, J.J., 2013. Health disparities and the cancer survivor. Seminars in Oncology, 40(6), pp.796-803. Available at: http://dx.doi.org/10.1053/j.seminoncol.2013.09.003.

Bodai, B.I. \& Tuso, P., 2015. Breast cancer survivorship: a comprehensive review of long-term medical issues and lifestyle recommendations. The Permanente journal, 19(2), pp.48-79.

Borstad, J.D. \& Szucs, K.A., 2012. Three-dimensional scapula kinematics and shoulder function examined before and after surgical treatment for breast cancer. Human Movement Science, 31(2), pp.408-418.

Breckenridge, J.D. \& McAuley, J.H., 2011. Shoulder Pain and Disability Index (SPADI). Journal of Physiotherapy, 57(3), p.197.

Cantarero-Villanueva, I. et al., 2011. Associations among musculoskeletal impairments, depression, body image and fatigue in breast cancer survivors within the first year after treatment. European Journal of Cancer Care, 20(5), pp.632-639.

Cotlar, A.M., Dubose, J.J. \& Rose, D.M., 2003. History of surgery for breast cancer: Radical to the sublime. Current Surgery, 60(3), pp.329-337.

Dawson, J. et al., 2009. The Oxford shoulder score revisited. Archives of Orthopaedic and Trauma Surgery, 129(1), pp.119-123.

Dean, L. et al., 2015. Black Breast Cancer Survivors Experience Greater Upper Extremity Disability. 
Breast Cancer Res Treat, 154(1), pp.117-125.

Fleissig, A. et al., 2006. Post-operative arm morbidity and quality of life. Results of the ALMANAC randomised trial comparing sentinel node biopsy with standard axillary treatment in the management of patients with early breast cancer. Breast Cancer Research and Treatment, 95(3), pp.279-293.

Freitas-Silva, R. et al., 2010. Comparison of quality of life, satisfaction with surgery and shoulder-arm morbidity in breast cancer survivors submitted to breast-conserving therapy or mastectomy followed by immediate breast reconstruction. Clinics, 65(8), pp.781-787.

Gosselink, R. et al., 2003. Recovery of upper limb function after axillary dissection. Journal of Surgical Oncology, 83(4), pp.204-211.

Gritsenko, V. et al., 2015. Feasibility of using low-cost motion capture for automated screening of shoulder motion limitation after breast cancer surgery. PLOS ONE, 10(6), pp.1-9.

De Groef, A. et al., 2016. Arm lymphoedema and upper limb impairments in sentinel node-negative breast cancer patients: A one year follow-up study. The Breast, 29, pp.102-108.

Harrington, S. et al., 2011. Comparison of shoulder flexibility, strength, and function between breast cancer survivors and healthy participants. Journal of Cancer Survivorship, 5(2), pp.167-174.

Hayes, S.C. et al., 2010. Upper-body morbidity following breast cancer treatment is common, may persist longer-term and adversely influences quality of life. Health and Quality of Life Outcomes, 8(1), p.92.

Van Der Heijden, G.J.M.G., Leffers, P. \& Bouter, L.M., 2000. Shoulder disability questionnaire design and responsiveness of a functional status measure. Journal of Clinical Epidemiology, 53(1), pp.29-38.

Helms, G. et al., 2009. Shoulder-arm morbidity in patients with sentinel node biopsy and complete 
axillary dissection - data from a prospective randomised trial. The Journal of Cancer Surgery, 35, pp.696-701.

Hendley, Y. et al., 2011. Differences in Weight Perception Among Blacks and Whites. Journal of Women's Health, 20(12), pp.1805-1811. Available at:

http://www.liebertonline.com/doi/abs/10.1089/jwh.2010.2262.

Herbst, M.C., 2016. Cancer Association of South Africa (CANSA) Fact Sheet on the Incidence of Cancer Among Females from 2000 to 2011,

Hidding, J.T. et al., 2014. Treatment related impairments in arm and shoulder in patients with breast cancer: A systematic review. PLOS ONE, 9(5).

Hopwood, P. et al., 2010. Comparison of patient-reported breast, arm, and shoulder symptoms and body image after radiotherapy for early breast cancer: 5-year follow-up in the randomised Standardisation of Breast Radiotherapy (START) trials. The Lancet Oncology, 11(3), pp.231-240.

Hudak, P., Amadio, P. \& Bombardier, C., 1996. Development of an upper extremity outcome measure: the DASH (disabilities of the arm, shoulder and hand) The Upper Extremity Collaborative Group (UECG). Am J Ind Med, 30(3), p.372.

International Agency for Research on Cancer (IARC), Globocan 2012: Estimated Cancer Incidence, Mortality and Prevalence Worldwide in 2012. Available at: http://globocan.iarc.fr/Pages/fact_sheets_population.aspx [Accessed February 24, 2017]. Jemal, A., Bray, F. \& Ferlay, J., 2011. Global Cancer Statistics: 2011. CA Cancer J Clin, 61, pp.69-90. Johansen, S. et al., 2014. Arm and shoulder morbidity following surgery and radiotherapy for breast cancer. Acta Oncologica, 53(4), pp.521-529.

Koehler, L.A. et al., 2015. Movement, Function, Pain, and Postoperative Edema in Axillary Web Syndrome. Phys Ther., 95(10), pp.1345-1353. 
Kootstra, J.J. et al., 2013. A longitudinal study of shoulder and arm morbidity in breast cancer survivors 7 years after sentinel lymph node biopsy or axillary lymph node dissection. Breast Cancer Research and Treatment, 139(1), pp.125-134.

Langford, D.J. et al., 2014. Persistent arm pain is distinct from persistent breast pain following breast cancer surgery. Journal of Pain, 15(12), pp.1238-1247.

LeBlanc, M. et al., 2014. Validation of quick DASH outcome measure in breast cancer survivors for upper extremity disability. Arch Phys Med Rehabil, 95(3), pp.493-498.

Levangie, P.K. \& Drouin, J., 2009. Magnitude of late effects of breast cancer treatments on shoulder function: A systematic review. Breast Cancer Research and Treatment, 116(1), pp.1-15.

Levy, E.W. et al., 2012. Predictors of functional shoulder recovery at 1 and 12 months after breast cancer surgery. Breast Cancer Research and Treatment, 134(1), pp.315-324.

Liu, C. et al., 2009. Late morbidity associated with a tumour-negative sentinel lymph node biopsy in primary breast cancer patients: a systematic review. European journal of cancer, 45(9), pp.1560-1568. Available at: http://dx.doi.org/10.1016/j.ejca.2009.02.012.

Mansel, R.E. et al., 2006. Randomized multicenter trial of sentinel node biopsy versus standard axillary treatment in operable breast cancer: The ALMANAC trial. Journal of the National Cancer Institute, 98(9), pp.599-609.

Marcus, T.S., Lunda, S. \& Fernandez, L., 2013. Delayed breast cancer presentation: Hospital data should inform proactive primary care. African Journal of Primary Health Care and Family Medicine, 5(1), pp.1-7.

McNeely, M.L. et al., 2010. Exercise interventions for upper-limb dysfunction due to breast cancer treatment. Cochrane database of systematic reviews (Online), (6), p.CD005211.

Miaskowski, C. et al., 2014. Identification of patient subgroups and risk factors for persistent 
arm/shoulder pain following breast cancer surgery. European Journal of Oncology Nursing, 18(3), pp.242-253.

Monleon, S. et al., 2016. Shoulder Strength Changes One Year After Axillary Lymph Node Dissection or Sentinel Lymph Node Biopsy in Patients With Breast Cancer. Archives of Physical Medicine and Rehabilitation, 97(6), pp.953-963.

Mutebi, M. \& Edge, J., 2014. Stigma, survivorship and solutions: Addressing the challenges of living with breast cancer in low-resource areas. South African Medical Journal, 104(5), pp.383-385.

National Health Laboratory Service, 2011. 2011 National Cancer Registry, Available at: http://www.cansa.org.za/south-african-cancer-statistics/.

Nesvold, I. et al., 2009. Arm and shoulder morbidity in breast cancer patients after breast-conserving therapy versus mastectomy. , (June 2017).

Nesvold, I.L. et al., 2009. Kwan's arm problem scale: Psychometric examination in a sample of stage II breast cancer survivors. Breast Cancer Research and Treatment, 117(2), pp.281-288.

Paul, A. et al., 2004. A comparison of four shoulder-specific questionnaires in primary care. Annals of the rheumatic diseases, 63(10), pp.1293-9.

Peintinger, F. et al., 2003. Comparison of quality of life and arm complaints after axillary lymph node dissection vs sentinel lymph node biopsy in breast cancer patients. British Journal of Cancer, 89(4), pp.648-652.

Poggi, M.M. et al., 2003. Eighteen-year results in the treatment of early breast carcinoma with mastectomy versus breast conservation therapy: The National Cancer Institute randomized trial. Cancer, 98(4), pp.697-702.

Roach, K. et al., 1991. Development of a shoulder pain and disability index. Arthritis Care Res, 4(4), pp.143-9. 
Roy, J.S., Macdermid, J.C. \& Woodhouse, L.J., 2009. Measuring shoulder function: A systematic review of four questionnaires. Arthritis Care and Research, 61(5), pp.623-632.

Shamley, D., 2015. A Cross-Disciplinary Look at Shoulder Pain and Dysfunction after Treatment for Breast Cancer. Int J Cancer Clin Res, 1(9).

Shamley, D. et al., 2009. Three-dimensional scapulothoracic motion following treatment for breast cancer. Breast Cancer Research and Treatment, 118(2), pp.315-322.

Shamley, D., Lascurain-Aguirrebena, I. \& Oskrochi, R., 2014. Clinical Anatomy of the Shoulder After Treatment for Breast Cancer. Clinical Anatomy, 27, pp.467-477.

Shamley, D., Lascurain-aguirrebeña, I. \& Oskrochi, R., 2012. Shoulder morbidity after treatment for breast cancer is bilateral and greater after mastectomy. Acta Oncologica, 51(8), pp.1045-1053.

Shamley, D. \& Robb, K., 2015. An early warning surveillance programme for detecting upper limb deterioration after treatment for breast cancer : A novel technology supported system. $B M C$ Cancer, pp.1-4.

Shamley, D.R. et al., 2007. Changes in shoulder muscle size and activity following treatment for breast cancer. Breast Cancer Research and Treatment, 106(1), pp.19-27.

Shamley, D.R. et al., 2005. Delayed versus immediate exercises following surgery for breast cancer: A systematic review. Breast Cancer Research and Treatment, 90(3), pp.263-271.

Smoot, B. et al., 2016. Predictors of Altered Upper Extremity Function During the First Year After Breast Cancer Treatment. American Journal of Physical Medicine \& Rehabilitation, p.1.

Straub, J.M. et al., 2015. Radiation-induced fibrosis: mechanisms and implications for therapy. J Cancer Res Clin Oncol, 141(11), pp.1985-1994.

The American College of Obstetricians and Gynaecologists, 2017. Clinical Management Guidelines for Obstetrician - Gynecologists Breast Cancer Risk Assessment and Screening in Average-Risk 
Women. , 130(122), pp.1-16.

Torres-Lacomba, M. et al., 2015. Spanish cultural adaptation and validation of the shoulder pain and disability index, and the oxford shoulder score after breast cancer surgery. Health and Quality of Life Outcomes, 13(1), p.63.

Tosello, G. et al., 2014. Breast surgery for metastatic breast cancer. Cochrane Database of Systematic Reviews, (9).

UpToDate, Breast cancer guide to diagnosis and treatment. Available at: https://www.uptodate.com/contents/breast-cancer-guide-to-diagnosis-and-treatmentbeyond-the-basics [Accessed February 26, 2017].

Williams, J., Holleman, D. \& Simel, D., 1995. Measuring shoulder function with the Shoulder Pain and Disability Index (SPADI). J Rheumatol, 22(4), p.1995.

Yeung, W.M., McPhail, S.M. \& Kuys, S.S., 2015. A systematic review of axillary web syndrome (AWS). Journal of Cancer Survivorship, 9(4), pp.576-598. 
PART B

LITERATURE REVIEW 


\section{Aim and Search Strategy}

The aim of this landscape literature review is to explore what is known about breast cancer treatment and resultant shoulder morbidities. The search strategy included a comprehensive search of several bibliographic databases (including Cochrane Library; Medline via PubMed, EBSCO, Scopus) and grey literature sources. All relevant studies available by July 2017 were included, regardless of publication status. Text words and Medical Subject Heading (MeSH) terms were used, and the literature search strategy was adapted to suit each database. A combination of the following terms were included: Breast Neoplasms, Unilateral Breast Neoplasms, Breast cancer, Shoulder, Shoulder Pain, Shoulder morbidity, Shoulder pain, Shoulder weakness.

\section{Breast Cancer Incidence}

Breast cancer is the most frequently diagnosed cancer and leading cause of cancer death among women in both low-to-middle income countries (LMICs) and high-income countries (HICs) (Jemal et al. 2011). Approximately half the breast cancer cases and $60 \%$ of the deaths are estimated to occur in LMICs (Jemal et al. 2011). Recent data from the United States (US) shows that breast cancer accounts for approximately one third of cancer diagnosed in women, with a lifetime risk of developing breast cancer of one in eight women (The American College of Obstetricians and Gynaecologists 2017). Data from the 2011 South African National Cancer Registry reports an incidence of breast cancer in women accounting for $21.46 \%$ of all cancers in females, with the greatest incidence occurring between the ages of 45-64 years (Herbst 2016; National Health Laboratory Service 2011). When broken down according to race, breast cancer accounts for similar proportions of total cancer in Black African and Caucasian women (20.87\% for Black African and 19.89\% for Caucasian, respectively) with larger proportions in Asians (35.44\%) and mixed ancestry women (26.63\%) (National Health Laboratory Service 2011). 
Internationally, there has been a considerable reduction in mortality due to breast cancer in the past 50 years (The American College of Obstetricians and Gynaecologists 2017). It is estimated that of the 252,710 new cases of breast cancer diagnosed in women in the US in 2017, 16\% of these will result in death (The American College of Obstetricians and Gynaecologists 2017). Similarly within South Africa, mortality is estimated to be $15.9 \%$ according to data from 2012 (International Agency for Research on Cancer (IARC) n.d.). Coupled with that, the 5-year survival rate is substantially higher compared to the 1970's (International Agency for Research on Cancer (IARC) n.d.). Reduction in mortality is attributed to early detection with the use of screening programmes, and improvements in breast cancer treatment, including new therapies (The American College of Obstetricians and Gynaecologists 2017; UpToDate n.d.). However, international variation in incidence and survival rates still exist due to differences in reproductive and hormonal factors, and the availability of early detection services (UpToDate n.d.). In LMICs such as South Africa, many patients present with advanced disease in addition to a lack of access to newest treatment options that may be available in HICs (Mutebi \& Edge 2014; Marcus et al. 2013).

\section{Breast Cancer Treatment}

The medical management of breast cancer includes surgery, radiotherapy, chemotherapy, biological agents, endocrine (hormonal) therapy, and/or a combination of these (Tosello et al. 2014). There are several surgical treatment options including radical mastectomy (removal of the breast, lymph nodes and adjacent muscular tissue), modified radical mastectomy (MRM; removal of entire breast including axillary lymph nodes but not the muscular tissue) and breast conserving surgery (BCT) which is also known as lumpectomy or wide local excision (WLE) (Cotlar et al. 2003). BCT was introduced in order to preserve the breast whilst achieving the same outcomes in terms of overall survival and disease-free survival as mastectomy, and several randomized controlled trials (RCTs) with long-term follow-up have demonstrated that BCT and mastectomy offer comparable survival (Poggi et al. 2003). 
The use of axillary surgery (Axillary Lymph Node Dissection (ALND) or Sentinel Node Biopsy (SNB)) is associated with substantial morbidity and may lead to short- and long-term complications, including infection, wound healing problems, shoulder stiffness, pain and arm swelling (Peintinger et al. 2003). Many patients receive surgery in combination with other treatments such as radiotherapy, chemotherapy, targeted therapy, and/or hormonal therapy.

\section{Breast Cancer Treatment Morbidity and Mortality}

Despite advances in survival due to improved treatment options, breast cancer surgery can result in shortterm and long-term complications, both physical and psychological (Borstad \& Szucs 2012; Freitas-Silva et al. 2010; Cantarero-Villanueva et al. 2011). Psychological complications may include depression, difficulties at work and anxiety (Freitas-Silva et al. 2010). From a physical perspective, BCT and mastectomy may result in impaired shoulder function including lymphoedema, pain, decreased range of motion (ROM), tightness, weakness, pain, numbness and Axillary Web Syndrome (AWS; also known as cording) (Freitas-Silva et al. 2010; De Groef et al. 2016; Shamley 2015; Koehler et al. 2015). AWS presents as a visible palpable web of axillary skin which can feel like a rope and is associated with early ROM shoulder restrictions, tightness and pain during shoulder abduction (Koehler et al. 2015; Yeung et al. 2015). Patients experiencing shoulder and arm problems have significantly reduced functional use of their upper limb, which has a direct impact on their quality of life, ability to return to work, difficulty sleeping and functional activities, particularly overhead reaching (Shamley 2015; Borstad \& Szucs 2012).

There is large variability regarding the severity and onset of upper limb symptoms, occurring both in the short- and long-term period post-surgery (Hidding et al. 2014; Gosselink et al. 2003). Reduced ROM, pain and lymphoedema are the most commonly described shoulder morbidities (Hidding et al. 2014). Shoulder mobility is less often impaired after SNB compared to ALND, with up to $87 \%$ of breast cancer survivors (BCS) having flexion and abduction ROM losses after ALND compared with $45 \%$ of those with SNB (Borstad 
\& Szucs 2012). Even with the advent of less invasive surgery, a proportion of BCS will continue to experience upper limb limitations 2 or more years after treatment (Levangie \& Drouin 2009), and may be present for up to six years post-surgery (Shamley et al. 2012; Shamley et al. 2009).

\section{Shoulder Morbidity}

\section{Reduction in Range Of Motion (ROM)}

A systematic review of arm and shoulder morbidity in patients treated for breast cancer with ALND found reduction in ROM ranging from 1-67\% (Hidding et al. 2014). Contrastingly, in patients treated with SNB, ROM occurred with a lower frequency of $6 \%-31 \%$ of patients after 12 months (Hidding et al. 2014). A prospective study of 115 women post-surgery for breast cancer found that more than $60 \%$ had ROM impairments in flexion and abduction and nearly $25 \%$ experienced ROM loss in external rotation at month 1 (Levy et al. 2012).

Risk factors for reduced ROM include ALND, a greater number of lymph nodes removed, cording, seroma, mastectomy, stage II, hand dominance, BMI > 25 and older age (Hidding et al. 2014). Mastectomy was associated with a 5.67 times increased odds of reduced ROM when compared to lumpectomy (Hidding et al. 2014). Similarly, grade I level evidence shows an increased odds of reduced ROM with radiotherapy when compared to no radiotherapy (odds ratios ranging from 2.09 - 12.30) (Hidding et al. 2014; Levangie \& Drouin 2009). The use of chemotherapy was associated with a $27 \%$ reduction in the odds of ROM reduction when compared with not receiving chemotherapy (Hidding et al. 2014).

\section{Reduction in muscle strength}

Reduced muscle strength has been reported in $17-28 \%$ of patients, with a greater proportion in those having received ALND (Hidding et al. 2014). Unlike reduced ROM with older age as a risk factor, muscle strength impairment has been associated with younger age $(<50$ years) (Hidding et al. 2014). Similar to reduced ROM, chest radiotherapy was associated with an increased odds between 1.70 and 6.83 (Hidding 
et al. 2014). Concurrent treatment with radiotherapy and chemotherapy (compared to sequential therapy) was also associated with a higher odds (Hidding et al. 2014).

\section{Pain}

Pain occurs between 9\%-68\%, with a greater incidence in those with ALND compared to SNB (Hidding et al. 2014). When compared to no radiotherapy, chest radiotherapy pain has been reported in $26 \%$ vs. $4 \%$ of patients (OR $=7.10)$, up to 13 years post-surgery (Hidding et al. 2014). Likewise, hormonal therapy and radiotherapy have been shown to be the greater risk for pain (Hidding et al. 2014). Similar to reduced muscle strength, concurrent radiotherapy and chemotherapy (compared to sequential treatment) is associated with a greater incidence of pain (Hidding et al. 2014). These findings may be similar as pain has been correlated with decreased muscle strength and ROM (Hidding et al. 2014). Contrasting to ROM reduction, chemotherapy has been associated with a 3 times greater odds of pain compared to no chemotherapy (Hidding et al. 2014). In those patients with pre-existing pain prior to surgery, they are 5 times more likely to experience post-operative and prolonged pain (Hidding et al. 2014).

\section{Lymphoedema}

Percentages of patients with lymphoedema ranges from 3\%-13\% for the first year post-surgery to 5\%-35\% in follow up (Hidding et al. 2014). ALND and high BMI are associated with an increased risk of lymphoedema, with a risk ratio of 3.47 for ALND and an odds ratio of 4.12 for BMI $\geq 30$ (Freitas-Silva et al. 2010; Hidding et al. 2014). Mastectomy, radiotherapy, and chemotherapy are also associated with a greater risk of developing lymphoedema (Hidding et al. 2014), in addition to a higher number of metastatic axillary lymph nodes (Freitas-Silva et al. 2010).

Lymphoedema was compared in 44 women with BCT and 26 women with modified radical mastectomy and immediate breast reconstruction (MRM+IBR) by measuring the circumference of both arms (FreitasSilva et al. 2010). The prevalence of lymphoedema in the total population was $15.7 \%$, with no significant difference between treatment modalities ( $12 \%$ for $M R M+\mid B R$ and $18 \%$ for $B C T, p=0.66)$ 
(Freitas-Silva et al. 2010). However, in a study comparing MRM ( $n=186)$ or BCT ( $n=77)$ with radiotherapy \pm chemotherapy \pm hormonal treatment (all had ALND), there was a significant difference between the prevalence of lymphoedema in the BCT group (8\%) compared to the RM group (20\%) (I. Nesvold et al. 2009). Many studies report this inconsistency between surgery type and lymphoedema, and this may stem from the differing criteria used in addition to time elapsed between surgery and analysis (FreitasSilva et al. 2010).

\section{Reduction in Activities in Daily Living (ADL)}

ALND is associated with an increased risk of problems in performing daily activities when compared to SNB, according to level 2 evidence from a cohort study (Hidding et al. 2014). Similar to reduced ROM, older age is associated a greater risk of problems in performing daily activities when compared to younger people, with those between $65-74$ years at highest risk (Hidding et al. 2014). A cohort study found mastectomy with ALND to be associated with more problems conducting social activities compared to lumpectomy and ALND (Hidding et al. 2014). Radiotherapy, especially when the axilla was involved, has also been associated with a decrease in the degree of daily activities (Hidding et al. 2014).

\section{Predictors of Shoulder Morbidity}

Attempts to identify clinical risk factors have been hindered by the complexity of the condition and the many clinical variables involved in cancer management (Shamley \& Robb 2015; Shamley 2015). Several demographic and clinical characteristics contribute to the risk of developing shoulder pain and disability, such as age, tumour grade, and the type of treatment received. Moreover, risk profiles for early versus late shoulder effects differ. Early predictors of ROM impairment in a military population cohort included type of axillary surgery (ALND worse than SNB), number of nodes removed and mastectomy, whereas older age and high body mass index (BMI) are associated with reduced ROM at 1 year (Levy et al. 2012). 
A prospective study in the US evaluating demographic and clinical characteristics as predictors of change in shoulder ROM, grip strength, and functional interference found race, neoadjuvant chemotherapy, type of surgery and ALND as predictors of early onset, with living alone being an additional predictor over time (Smoot et al. 2016). This study evaluated upper extremity function 1 year after treatment, and thus these risk factors may or may not describe the predictors of long-term morbidity many years after treatment. Radiotherapy and chemotherapy have been linked to increased upper limb pain and dysfunction, suggesting a potential systemic cause of shoulder pain and dysfunction (Shamley 2015; Hidding et al. 2014). The acute effects of surgery, chemotherapy and radiotherapy all result in acute inflammation, skin changes and associated pain. Subsequent to the acute affects, shoulder morbidity remains a chronic condition, partly as a result of radiation-induced fibrosis (Straub et al. 2015).

\section{ALND vs. SNB}

Both ALND and SNB may result in shoulder impairments (Levangie \& Drouin 2009), however, SNB is associated with a decreased prevalence of upper limb impairments and lymphoedema when compared to ALND (De Groef et al. 2016). Reduced ROM and muscle strength, pain, lymphoedema and decreased degree of activities in daily living are most frequently reported in relation to ALND (Hidding et al. 2014), with approximately $30 \%$ of patients developing shoulder-arm morbidity on the operated side after ALND (De Groef et al. 2016; Helms et al. 2009). Similar results were found in the Axillary Lymphatic Mapping against Nodal Axillary Clearance (ALMANAC) trial which compared SNB $(n=424)$ to standard axillary treatment ( $n=405$ ) (Mansel et al. 2006). Post-operative arm morbidity and quality of life was assessed using the Functional Assessment of Cancer Therapy - Breast (FACT-B+4) instrument amended to include arm morbidity items, up to 18 months (Fleissig et al. 2006). At the end of the study, there was significantly more arm swelling and numbness in the standard group compared with the SNB group (14\% versus $7 \%$ for swelling and $19 \%$ versus $8.7 \%$ for numbness), which in turn affected quality of life (Fleissig et al. 2006). Additionally, $28.3 \%$ of patients in the standard group reported at least 1 arm problem compared with $16.9 \%$ in the SNB group ( $p<0.001$ ) (Fleissig et al. 2006). Older age and SNB had decreased effects on change in arm functioning scores from baseline to each of the study time points, although it is worth nothing that the 
age groups were not balanced with respect to tumour grade, primary surgery and adjuvant treatment (Fleissig et al. 2006). There did not appear to be a difference in frequency of morbidity when comparing surgery on dominant side versus non-dominant side (Fleissig et al. 2006). Furthermore, the sequential use of SNB followed by ALND was compared to SNB alone in 181 women (Helms et al. 2009). In both objective and subjective measures, SNB scored better than the sequential treatment group $(p<0.001$ for total scores) (Helms et al. 2009).

Furthermore, another study comparing changes in shoulder strength 1 year after ALND or SNB found that strength decreased significantly at the first month after ALND, without having recovered pre-surgery values after 1 year of follow-up whereas no significant loss of strength was observed for patients treated with SNB at one month or 1 year (Monleon et al. 2016). It is worth noting that statistically significant differences in baseline characteristics existed between the SNB and ALND groups for BMI, type of surgery, tumour size, excised nodes and chemotherapy, which have also been associated with shoulder morbidity outcomes (Monleon et al. 2016). Similar to the data from De Groef et al and Helms et al, these data derive from studies with 1 year and 3 year follow up data, respectively, and therefore longer-term data would be useful to understand the long-term burden. Inherent in all of these observational studies is the potential for loss to follow up of those patients which may introduce a bias towards those seeking treatment for shoulder morbidity and pain management.

A longitudinal study of 100 women 1 year after SNB found $49 \%$ had impaired shoulder function as measured by the Disability of Arm, Shoulder and Hand (DASH) questionnaire, with shoulder morbidities changing significantly over the 1 year period (De Groef et al. 2016). Importantly, patients with a higher BMI had a significantly greater decrease in shoulder function (De Groef et al. 2016).

\section{Radiotherapy}

Radiotherapy has been associated with impaired shoulder function and movement, with more extensive radiotherapy associated with long-term shoulder morbidity (Levangie \& Drouin 2009). Notably, patients 
receiving axillary radiotherapy (as opposed to chest wall radiotherapy alone) are at higher risk of late arm morbidity and greater disability of shoulder mobility and activities of daily living (ADL) (Levangie \& Drouin 2009; Gosselink et al. 2003). This may be due to diminished tissue healing or increased tissue fibrosis and stiffness affecting shoulder motion (Shamley et al. 2009; Gosselink et al. 2003). Various radiotherapy regimes were compared in the Standardisation of Breast Radiotherapy (START) trial, which randomised patients to different regimens and collected quality of life data for 2208 patients over the 5 years of followup (Hopwood et al. 2010). Arm and shoulder pain was reported in approximately a third of patients, with scores not differing between the regimens (Hopwood et al. 2010). Of patients who received locoregional radiotherapy \pm chemotherapy \pm hormone therapy, $91 \%$ had some degree of arm/shoulder morbidity (Johansen et al. 2014). Dose level of radiotherapy was not associated with clinical endpoints, however, weak associations were shown between receiving approximately 15+ gray (Gy) and arm pain, arm stiffness, swollen arm, use of arm, numbness and shoulder abduction (Johansen et al. 2014).

\section{Race}

The impact of race was compared in a study in the US post-surgery for breast cancer. Participant who were Asian, Pacific Islander, Black or Hispanic (collectively compared as a group, 'other') were at a greater risk of developing adverse shoulder outcomes when compared to White women (Langford et al. 2014; Miaskowski et al. 2014; Smoot et al. 2016). The 'other' group reported worse shoulder morbidity, however, many of them also present with advanced disease requiring aggressive treatment, which may play a role in differences seen (Smoot et al. 2016).

The impact of race on disability was compared among BCS using a validated scale called QuickDASH (Dean et al. 2015). Patients self-identified as Black (16\%) or White (84\%) (Dean et al. 2015). Black women had 7.3 points higher average compared to White women ( $p<0.001$ ) (Dean et al. 2015). After adjusting for key demographic and clinical factors (e.g. BMI, age, education, cancer treatment, months since diagnosis), Black women had 4 points higher average $(p=0.04)$ (Dean et al. 2015). Interestingly, Black women presented with factors associated with greater upper extremity disability including increased BMI, older 
age, more advanced disease at diagnosis, and underuse of SNB when compared with White women (Dean et al. 2015). It is important to note that mediation analysis suggested that BMI attenuated the association between race and disability by $40 \%$ thus reducing the strength of the association between race and disability (Dean et al. 2015).

Race and arm pain was considered in another US study which evaluated demographic and clinical characteristics to assess differences in mild or moderate arm pain scores (Langford et al. 2014). Women who experienced moderate pain had significantly fewer years of education, lower Karnofsky Performance Status (KPS) scores, and higher comorbidity scores than those women with mild pain (Langford et al. 2014). Additionally, those in the moderate pain group had lower annual incomes, a higher number of postoperative complications, higher rates of depression (Langford et al. 2014). A greater proportion of black women experienced moderate pain whereas a greater proportion of white women experienced mild pain (Langford et al. 2014; Miaskowski et al. 2014). A study of 287 women in Australia found older age, lower socioeconomic position, treatment on the dominant side, mastectomy, more extensive lymph node removal and having lymphoedema correlated with impairments in upper-body function (Hayes et al. 2010). Notably, none of these studies were of a South African Black population, and therefore inferences to our local population need to be taken with caution.

In summary, consideration needs to be given to racial disparities with regards to cancer diagnosis and treatment. Differences relate to cancer stage at diagnosis, treatment options, survival, and quality of life outcomes (Blinder \& Griggs 2013). Minorities, such as Black women, tend to be diagnosed with more advanced disease, are more likely to receive inferior treatment, and experience greater morbidity and mortality related to cancer and its treatment (Blinder \& Griggs 2013).

\section{Measuring Shoulder Pain and Disability}


Many tools have been developed to measure arm and/or shoulder pain and disability, including the Shoulder Pain and Disability Index (SPADI), Disabilities of the Arm, Shoulder and Hand (DASH), Oxford Shoulder Score (OSS), and Shoulder Rating Questionnaire (SRQ) (Roach et al. 1991; Breckenridge \& McAuley 2011; Dawson et al. 2009; LeBlanc et al. 2014; Anon n.d.). Importantly, using shoulder-specific tools to measure function may help with rehabilitation (Borstad \& Szucs 2012). The challenge of using objective measures rather than patient self-report is that they may fail to capture the extent that the problems have on quality of life (Fleissig et al. 2006).

\section{Shoulder Pain and Disability Index (SPADI)}

SPADI is a self-administered index consisting of 13 items divided into two subscales; 5 for pain and 8 for disability (Roach et al. 1991). SPADI total and subscale scores are highly negatively correlated with shoulder ROM (Roach et al. 1991). Validation studies have shown internal consistency and reliability, and thus confirming its usefulness for both clinical and research purposes (Roach et al. 1991). The questionnaire is easy to complete and imposes very little burden on the patient (Torres-Lacomba et al. 2015). SPADI has been adapted cross-culturally into Spanish, and has shown excellent reliability and validity (test-retest reliability of 0.992 and Cronbach's alpha of 0.965) (Torres-Lacomba et al. 2015).

The SPADI index has been shown to identify key functional limitations in BCS associated with high, intermediate and low levels of pain and correlated with specific altered muscle activity and scapula deviation patterns, enabling it to be a surrogate marker for the early identification of patients at risk of developing advanced shoulder pain and dysfunction (Shamley \& Robb 2015). A study comparing a face version of the SPADI (using the Wong-Baker FACES scale) to the numerical SPADI scale in South African BCS confirmed excellent concurrent validity, internal consistency and test-retest reliability (manuscript submitted). 


\section{Oxford Shoulder Score (OSS)}

The Oxford Shoulder Score (OSS) is a valid and reliable patient-reported scale primarily developed for the assessment of outcomes of shoulder surgery in randomised trials, developed with the intention of minimising the influence of other co-morbidities (Dawson et al. 2009). OSS has been used in cohort studies, audits and registries (Dawson et al. 2009). Similar to SPADI, it is easy to complete and has been translated into Spanish with good reliability and validity (test-retest reliability of 0.974 and Cronbach's alpha of 0.947 ) (Torres-Lacomba et al. 2015).

\section{Disabilities of the Arm, Shoulder and Hand (DASH)}

Disabilities of the Arm, Shoulder and Hand (DASH) is a self-report 30-item questionnaire used to measure physical function and symptoms in any or all joints of the upper limb (Anon n.d.). It includes two optional, four-item modules in useful for athletes, performing artists and other workers whose jobs require a high degree of physical performance (Anon n.d.). It is one of the most commonly used patient reported outcomes (PRO) measures for upper extremity assessment, however, is not specific to shoulder only (LeBlanc et al. 2014). However, despite its common usage in breast cancer survivorship research, DASH psychometric properties have not been investigated in this population (LeBlanc et al. 2014).

The QuickDASH is a shortened, convenient version of DASH comprising 11 items to measure physical function and symptoms in people with any or multiple musculoskeletal disorders of the upper limb (Anon n.d.). DASH and QuickDASH are both valid, reliable and responsive and useful for daily clinical practice and/or research purposes (Anon n.d.; Hudak et al. 1996). QuickDASH has also been shown to be valid and reliable in assessing upper extremity disability in breast cancer patients (LeBlanc et al. 2014) 


\section{Shoulder Rating Questionnaire (SRQ)}

Shoulder Rating Questionnaire (SRQ) is a valid and reliable 21 question instrument used to examine subjective perception of shoulder function and has shown to be responsible in patients with many shoulder pathologies (Borstad \& Szucs 2012). Several domains are measured on a $10 \mathrm{~cm}$ VAS or 5 point Likert scale, including global assessment, pain, daily activities, recreational and athletic activities, work, and satisfaction (Borstad \& Szucs 2012).

\section{Kwan's arm problem scale (KAPS)}

Kwan's Arm Problem self-rating scale (KAPS) is used for the assessment of arm/shoulder problems and lymphoedema in patients treated for breast cancer with high reliability and validity (I. L. Nesvold et al. 2009). There are 13 items in total; 8 items rating problems with arm/shoulder function, pain, stiffness and swelling, and 5 items rating impairment of ADL due to arm/shoulder problems (I. L. Nesvold et al. 2009). Items are rated on a 5 point Likert scale and are summed up to give a total score (I. L. Nesvold et al. 2009).

\section{Shoulder Disability Questionnaire (SDQ)}

The Shoulder Disability Questionnaire (SDQ) is a self-reported 16 item questionnaire evaluating functional status limitation in patients with soft tissue shoulder disorders (Van Der Heijden et al. 2000). It is quick and easy to complete, however, has primarily been used for patients in in a randomized placebo-controlled trial on ultrasound and electrotherapy as adjuvants to exercise therapy (Van Der Heijden et al. 2000).

\section{Gaps in Research and Moving Forward}


There are no formal guidelines in South Africa for how to manage upper limb morbidities for BCS. Rehabilitation programmes are resource intensive and thus not implemented in standard cancer care pathways (Shamley \& Robb 2015). Patients with shoulder problems often present to musculoskeletal practitioners who may not link the impairment to prior breast cancer treatment, particularly because these patterns of movement deviations resemble those seen in known shoulder conditions (Shamley et al. 2014; Shamley \& Robb 2015). The challenge is that it is not feasible in many cancer centres to have a dedicated professional performing screening and treatment of all patients for motion impairments (Gritsenko et al. 2015).

The potential to identify predictors early on, particularly modifiable preoperative predictors, could have a significant impact on recovery of function after breast cancer treatment (Smoot et al. 2016; Hidding et al. 2014; Shamley 2015). Knowledge of short term biomechanical changes at the shoulder will inform treatment decisions and may help prevent the development of shoulder pathology (Borstad \& Szucs 2012). Additionally, a knowledge of risk factors provides important information for designing targeted rehabilitation programmes (Monleon et al. 2016). Due to advances in treatment options and modalities, more women are surviving long term and therefore assessing upper extremity disability is an increasingly important issue, coupled with the fact that these disabilities persist into the long-term (Shamley et al. 2012; Hidding et al. 2014; Harrington et al. 2011).

Therefore, long term, cost-effective surveillance programmes should be available to all patients and should identify those at risk of developing morbidity and target the interventions at the high risk population of patients (Shamley \& Robb 2015). Physical therapy and exercise are effective interventions for improving function and overcoming arm morbidities such as ROM, strength, and oedema (Gritsenko et al. 2015; Shamley et al. 2005). This would also have a significant impact on the public health burden of these patients, who are unable to return to work and require public health resources. A proposal of risk stratification may be employed to reduce cost and target those most at risk, including risk ascertainment a 
few weeks post-surgery, several months post-surgery and long-term follow up, up to 10 years via a combination of questionnaires and online self-assessment (Shamley \& Robb 2015). 


\section{References}

Anon, 2014. Race, Ethnicity and Language in South Africa | World Elections. Available at:

https://welections.wordpress.com/guide-to-the-2014-south-african-election/race-ethnicityand-language-in-south-africa/ [Accessed September 18, 2017].

Anon, The Disabilities of the Arm, Shoulder and Hand (DASH) Outcome Measure. Available at: http://www.dash.iwh.on.ca/about-dash [Accessed July 25, 2017].

Blinder, V.S. \& Griggs, J.J., 2013. Health disparities and the cancer survivor. Seminars in Oncology, 40(6), pp.796-803. Available at: http://dx.doi.org/10.1053/j.seminoncol.2013.09.003.

Bodai, B.I. \& Tuso, P., 2015. Breast cancer survivorship: a comprehensive review of long-term medical issues and lifestyle recommendations. The Permanente journal, 19(2), pp.48-79.

Borstad, J.D. \& Szucs, K.A., 2012. Three-dimensional scapula kinematics and shoulder function examined before and after surgical treatment for breast cancer. Human Movement Science, 31(2), pp.408-418.

Breckenridge, J.D. \& McAuley, J.H., 2011. Shoulder Pain and Disability Index (SPADI). Journal of Physiotherapy, 57(3), p.197.

Cantarero-Villanueva, I. et al., 2011. Associations among musculoskeletal impairments, depression, body image and fatigue in breast cancer survivors within the first year after treatment. European Journal of Cancer Care, 20(5), pp.632-639.

Cotlar, A.M., Dubose, J.J. \& Rose, D.M., 2003. History of surgery for breast cancer: Radical to the sublime. Current Surgery, 60(3), pp.329-337.

Dawson, J. et al., 2009. The Oxford shoulder score revisited. Archives of Orthopaedic and Trauma Surgery, 129(1), pp.119-123.

Dean, L. et al., 2015. Black Breast Cancer Survivors Experience Greater Upper Extremity Disability. Breast Cancer Res Treat, 154(1), pp.117-125.

Fleissig, A. et al., 2006. Post-operative arm morbidity and quality of life. Results of the ALMANAC 
randomised trial comparing sentinel node biopsy with standard axillary treatment in the management of patients with early breast cancer. Breast Cancer Research and Treatment, 95(3), pp.279-293.

Freitas-Silva, R. et al., 2010. Comparison of quality of life, satisfaction with surgery and shoulder-arm morbidity in breast cancer survivors submitted to breast-conserving therapy or mastectomy followed by immediate breast reconstruction. Clinics, 65(8), pp.781-787.

Gosselink, R. et al., 2003. Recovery of upper limb function after axillary dissection. Journal of Surgical Oncology, 83(4), pp.204-211.

Gritsenko, V. et al., 2015. Feasibility of using low-cost motion capture for automated screening of shoulder motion limitation after breast cancer surgery. PLOS ONE, 10(6), pp.1-9.

De Groef, A. et al., 2016. Arm lymphoedema and upper limb impairments in sentinel node-negative breast cancer patients: A one year follow-up study. The Breast, 29, pp.102-108.

Harrington, S. et al., 2011. Comparison of shoulder flexibility, strength, and function between breast cancer survivors and healthy participants. Journal of Cancer Survivorship, 5(2), pp.167-174.

Hayes, S.C. et al., 2010. Upper-body morbidity following breast cancer treatment is common, may persist longer-term and adversely influences quality of life. Health and Quality of Life Outcomes, 8(1), p.92.

Van Der Heijden, G.J.M.G., Leffers, P. \& Bouter, L.M., 2000. Shoulder disability questionnaire design and responsiveness of a functional status measure. Journal of Clinical Epidemiology, 53(1), pp.29-38.

Helms, G. et al., 2009. Shoulder-arm morbidity in patients with sentinel node biopsy and complete axillary dissection - data from a prospective randomised trial. The Journal of Cancer Surgery, 35, pp.696-701.

Hendley, Y. et al., 2011. Differences in Weight Perception Among Blacks and Whites. Journal of Women's Health, 20(12), pp.1805-1811. Available at: http://www.liebertonline.com/doi/abs/10.1089/jwh.2010.2262. 
Herbst, M.C., 2016. Cancer Association of South Africa (CANSA) Fact Sheet on the Incidence of Cancer Among Females from 2000 to 2011,

Hidding, J.T. et al., 2014. Treatment related impairments in arm and shoulder in patients with breast cancer: A systematic review. PLOS ONE, 9(5).

Hopwood, P. et al., 2010. Comparison of patient-reported breast, arm, and shoulder symptoms and body image after radiotherapy for early breast cancer: 5-year follow-up in the randomised Standardisation of Breast Radiotherapy (START) trials. The Lancet Oncology, 11(3), pp.231-240. Hudak, P., Amadio, P. \& Bombardier, C., 1996. Development of an upper extremity outcome measure: the DASH (disabilities of the arm, shoulder and hand) The Upper Extremity Collaborative Group (UECG). Am J Ind Med, 30(3), p.372.

International Agency for Research on Cancer (IARC), Globocan 2012: Estimated Cancer Incidence, Mortality and Prevalence Worldwide in 2012. Available at: http://globocan.iarc.fr/Pages/fact_sheets_population.aspx [Accessed February 24, 2017]. Jemal, A., Bray, F. \& Ferlay, J., 2011. Global Cancer Statistics: 2011. CA Cancer J Clin, 61, pp.69-90. Johansen, S. et al., 2014. Arm and shoulder morbidity following surgery and radiotherapy for breast cancer. Acta Oncologica, 53(4), pp.521-529.

Koehler, L.A. et al., 2015. Movement, Function, Pain, and Postoperative Edema in Axillary Web Syndrome. Phys Ther., 95(10), pp.1345-1353.

Kootstra, J.J. et al., 2013. A longitudinal study of shoulder and arm morbidity in breast cancer survivors 7 years after sentinel lymph node biopsy or axillary lymph node dissection. Breast Cancer Research and Treatment, 139(1), pp.125-134.

Langford, D.J. et al., 2014. Persistent arm pain is distinct from persistent breast pain following breast cancer surgery. Journal of Pain, 15(12), pp.1238-1247.

LeBlanc, M. et al., 2014. Validation of quick DASH outcome measure in breast cancer survivors for upper extremity disability. Arch Phys Med Rehabil, 95(3), pp.493-498.

Levangie, P.K. \& Drouin, J., 2009. Magnitude of late effects of breast cancer treatments on shoulder 
function: A systematic review. Breast Cancer Research and Treatment, 116(1), pp.1-15.

Levy, E.W. et al., 2012. Predictors of functional shoulder recovery at 1 and 12 months after breast cancer surgery. Breast Cancer Research and Treatment, 134(1), pp.315-324.

Liu, C. et al., 2009. Late morbidity associated with a tumour-negative sentinel lymph node biopsy in primary breast cancer patients: a systematic review. European journal of cancer, 45(9), pp.1560-1568. Available at: http://dx.doi.org/10.1016/j.ejca.2009.02.012.

Mansel, R.E. et al., 2006. Randomized multicenter trial of sentinel node biopsy versus standard axillary treatment in operable breast cancer: The ALMANAC trial. Journal of the National Cancer Institute, 98(9), pp.599-609.

Marcus, T.S., Lunda, S. \& Fernandez, L., 2013. Delayed breast cancer presentation: Hospital data should inform proactive primary care. African Journal of Primary Health Care and Family Medicine, 5(1), pp.1-7.

McNeely, M.L. et al., 2010. Exercise interventions for upper-limb dysfunction due to breast cancer treatment. Cochrane database of systematic reviews (Online), (6), p.CD005211.

Miaskowski, C. et al., 2014. Identification of patient subgroups and risk factors for persistent arm/shoulder pain following breast cancer surgery. European Journal of Oncology Nursing, 18(3), pp.242-253.

Monleon, S. et al., 2016. Shoulder Strength Changes One Year After Axillary Lymph Node Dissection or Sentinel Lymph Node Biopsy in Patients With Breast Cancer. Archives of Physical Medicine and Rehabilitation, 97(6), pp.953-963.

Mutebi, M. \& Edge, J., 2014. Stigma, survivorship and solutions: Addressing the challenges of living with breast cancer in low-resource areas. South African Medical Journal, 104(5), pp.383-385. National Health Laboratory Service, 2011. 2011 National Cancer Registry, Available at: http://www.cansa.org.za/south-african-cancer-statistics/.

Nesvold, I. et al., 2009. Arm and shoulder morbidity in breast cancer patients after breast-conserving therapy versus mastectomy. , (June 2017). 
Nesvold, I.L. et al., 2009. Kwan's arm problem scale: Psychometric examination in a sample of stage II breast cancer survivors. Breast Cancer Research and Treatment, 117(2), pp.281-288.

Paul, A. et al., 2004. A comparison of four shoulder-specific questionnaires in primary care. Annals of the rheumatic diseases, 63(10), pp.1293-9.

Peintinger, F. et al., 2003. Comparison of quality of life and arm complaints after axillary lymph node dissection vs sentinel lymph node biopsy in breast cancer patients. British Journal of Cancer, 89(4), pp.648-652.

Poggi, M.M. et al., 2003. Eighteen-year results in the treatment of early breast carcinoma with mastectomy versus breast conservation therapy: The National Cancer Institute randomized trial. Cancer, 98(4), pp.697-702.

Roach, K. et al., 1991. Development of a shoulder pain and disability index. Arthritis Care Res, 4(4), pp.143-9.

Roy, J.S., Macdermid, J.C. \& Woodhouse, L.J., 2009. Measuring shoulder function: A systematic review of four questionnaires. Arthritis Care and Research, 61(5), pp.623-632.

Shamley, D., 2015. A Cross-Disciplinary Look at Shoulder Pain and Dysfunction after Treatment for Breast Cancer. Int J Cancer Clin Res, 1(9).

Shamley, D. et al., 2009. Three-dimensional scapulothoracic motion following treatment for breast cancer. Breast Cancer Research and Treatment, 118(2), pp.315-322.

Shamley, D., Lascurain-Aguirrebena, I. \& Oskrochi, R., 2014. Clinical Anatomy of the Shoulder After Treatment for Breast Cancer. Clinical Anatomy, 27, pp.467-477.

Shamley, D., Lascurain-aguirrebeña, I. \& Oskrochi, R., 2012. Shoulder morbidity after treatment for breast cancer is bilateral and greater after mastectomy. Acta Oncologica, 51(8), pp.1045-1053.

Shamley, D. \& Robb, K., 2015. An early warning surveillance programme for detecting upper limb deterioration after treatment for breast cancer : A novel technology supported system. BMC Cancer, pp.1-4.

Shamley, D.R. et al., 2007. Changes in shoulder muscle size and activity following treatment for 
breast cancer. Breast Cancer Research and Treatment, 106(1), pp.19-27.

Shamley, D.R. et al., 2005. Delayed versus immediate exercises following surgery for breast cancer: A systematic review. Breast Cancer Research and Treatment, 90(3), pp.263-271.

Smoot, B. et al., 2016. Predictors of Altered Upper Extremity Function During the First Year After Breast Cancer Treatment. American Journal of Physical Medicine \& Rehabilitation, p.1.

Straub, J.M. et al., 2015. Radiation-induced fibrosis: mechanisms and implications for therapy. J Cancer Res Clin Oncol, 141(11), pp.1985-1994.

The American College of Obstetricians and Gynaecologists, 2017. Clinical Management Guidelines for Obstetrician - Gynecologists Breast Cancer Risk Assessment and Screening in Average-Risk Women. , 130(122), pp.1-16.

Torres-Lacomba, M. et al., 2015. Spanish cultural adaptation and validation of the shoulder pain and disability index, and the oxford shoulder score after breast cancer surgery. Health and Quality of Life Outcomes, 13(1), p.63.

Tosello, G. et al., 2014. Breast surgery for metastatic breast cancer. Cochrane Database of Systematic Reviews, (9).

UpToDate, Breast cancer guide to diagnosis and treatment. Available at: https://www.uptodate.com/contents/breast-cancer-guide-to-diagnosis-and-treatmentbeyond-the-basics [Accessed February 26, 2017].

Williams, J., Holleman, D. \& Simel, D., 1995. Measuring shoulder function with the Shoulder Pain and Disability Index (SPADI). J Rheumatol, 22(4), p.1995.

Yeung, W.M., McPhail, S.M. \& Kuys, S.S., 2015. A systematic review of axillary web syndrome (AWS). Journal of Cancer Survivorship, 9(4), pp.576-598. 


\section{Part C \\ JOURNAL READY MANUSCRIPT \\ Journal: Acta Oncologica}


Prevalence of Shoulder Morbidity after Treatment for Breast Cancer in South Africa ${ }^{1}$

\begin{abstract}
Introduction

Breast cancer is the most frequently diagnosed cancer and leading cause of cancer death among women, representing a considerable public health burden in South Africa and other low-middle income countries. Breast cancer management comprises of single or combination treatment including surgery, radiotherapy and chemotherapy. Short and long-term complications of these treatments include shoulder morbidities such as pain, decreased range of motion, tightness, weakness, pain, numbness and lymphoedema, and may be present for up to 6 years post-treatment. An understanding of baseline demographic and clinical risk factors can guide rehabilitation and management strategies for high risk patients.
\end{abstract}

\title{
Materials and Methods
}

This study was a cross-sectional analysis of the prevalence of shoulder pain and dysfunction in women attending their post-treatment annual follow up visit for unilateral breast carcinoma as measured by the Shoulder Pain and Disability Index (SPADI) questionnaire. The aim of this study was to quantify the burden of shoulder pain and disability in a tertiary academic hospital in Cape Town,

\footnotetext{
${ }^{1}$ Co-authors: Dr DS Shamley and Mr J Ramjith
} 
South Africa, and identify potential risk factors for the development of shoulder morbidity.

\section{Results}

The majority of patients were of mixed ancestry, had their left side affected, received Axillary Lymph Node Biopsy and had undergone Modified Radical Mastectomy. The mean age was 60 years with a mean follow-up since surgery of 6 years. Three in four patients reported a presence of any pain or disability while only $9 \%$ experienced severe pain and disability. Multivariable ordinal logistic regression analysis identified race, side, axillary surgery, chemotherapy and age as significant predictors of pain, and chemotherapy a significant predictor of disability.

\section{Discussion}

The substantial burden of shoulder morbidity in this population represents a significant public health burden. The use of identified clinical and demographic characteristics may guide in the development of survivorship programmes incorporating surveillance and management of these high risk patients.

Keywords: breast cancer, shoulder, morbidity, pain, disability, SPADI 


\section{Introduction}

Breast cancer is the most frequently diagnosed cancer and leading cause of cancer death among women in both low-to-middle income countries (LMICs) and high-income countries (HICs) (Jemal et al. 2011). Approximately half the breast cancer cases and $60 \%$ of the deaths are estimated to occur in LMICs (Jemal et al. 2011). According to the 2011 South African National Cancer Registry, breast cancer accounts for $21 \%$ of all cancers in females, with the greatest incidence occurring between the ages of 45-64 years (Herbst 2016; National Health Laboratory Service 2011). This is accompanied by a mortality rate of $16 \%$ from 2012 (International Agency for Research on Cancer (IARC) n.d.), representing a considerable public health burden in South Africa (Herbst 2016). In LMICs such as South Africa, many patients present with advanced disease and have a lack of access to newest treatment options that may be available in HICs (Mutebi \& Edge 2014; Marcus et al. 2013). Screening programmes, early diagnosis and new treatments have an impact on reducing the mortality associated with breast cancer (UpToDate n.d.).

The medical management of breast cancer includes surgery, radiotherapy, chemotherapy, biological agents, and hormonal therapy, as monotherapy or in combination (Tosello et al. 2014). These treatment modalities may result in short and long-term complications, including impaired shoulder function such as pain, decreased range of motion (ROM), tightness, weakness, pain, numbness and lymphoedema (Freitas-Silva et al. 2010; De Groef et al. 2016; Shamley 2015; Koehler et al. 2015). These complications affect activities of daily living (ADL) including the ability to return to work (Shamley 2015). Reduced ROM, pain and lymphoedema are the most commonly described shoulder morbidities (Hidding et al. 2014) that occur shortly after surgery (Fleissig et al. 2006) and may be present for up to six years post-surgery (Shamley 
et al. 2012; Shamley et al. 2009). The cause of shoulder pain and dysfunction is complex and multifactorial (Borstad \& Szucs 2012) and attempts to identify clinical risk factors are challenged by the complexity of the condition and its resemblance to other shoulder conditions (Shamley \& Robb 2015; Shamley 2015). Different treatment modalities are associated with varying levels of shoulder morbidity, such as a higher prevalence in those receiving Axillary Lymph Node Biopsy (ALNB) compared to Sentinel Node Biopsy (SNB), in those receiving mastectomy compared to breast-conserving therapy (BCT), and with the use of chemotherapy and radiotherapy (De Groef et al. 2016; Shamley 2015; Levangie \& Drouin 2009; Hidding et al. 2014; Smoot et al. 2016; Helms et al. 2009). Demographics associated with increased shoulder morbidity include the number of nodes removed, older age, the left side being affected and high body mass index (BMI) (Shamley et al. 2012; Shamley et al. 2009; Shamley et al. 2007; Levy et al. 2012). Additionally, Black race, fewer years of education and lower annual income have been associated with higher levels of pain (Langford et al. 2014).

The aim of this study was to quantify the burden of shoulder pain and disability in a tertiary academic hospital in Cape Town, South Africa, and identify potential risk factors for the development of shoulder morbidity.

\section{Materials and Methods}

\section{Methods}

Women attending their annual check-up at the breast clinic at Groote Schuur Hospital, Cape Town, South Africa, were approached to be included in the study. Informed consent was received for all participants prior to collection of data. Personal information was de-identified 
and each participant was assigned a study number. Patients were reviewed according to predetermined inclusion and exclusion criteria (see below), and upon informed consent, completed the Shoulder Pain and Disability Index (SPADI) questionnaire in the language of their choice. SPADI is a self-administered index consisting of 13 items divided into two subscales; 5 items for pain and 8 items for disability, which has shown consistency and reliability. The questionnaire is easy to complete and imposes very little burden on the patient. Those requiring assistance to complete the questionnaire were assisted by research staff fluent in the language of the participant. Additional clinical and demographic data was collected such as race (selfidentified), age, treatment protocol, tumour grade, side affected and number of involved nodes.

This study is a cross-sectional analysis of the prevalence of shoulder pain and disability in this sample of women. The primary objective of this study was to determine the prevalence of shoulder morbidity within a tertiary academic centre, in patients attending their post-treatment annual follow up visit for unilateral breast carcinoma. The secondary objective was to evaluate associations between shoulder morbidity and covariates such as treatment protocol and baseline demographics.

\section{Inclusion and exclusion criteria}

\section{Inclusion criteria:}

1. Women 18 years of age and older

2. $\geq 1$ year post surgery for unilateral carcinoma of the breast

\section{Exclusion criteria:}

1. Reconstructive surgery

2. Current or previous history of shoulder complex trauma, surgery, pathology or dysfunction 
3. Current or previous history of cervical neuropathy

\section{Statistical Considerations and Data Analysis}

\section{Sample size}

This was a convenience sample of women attending annual follow up appointments at the breast clinic at the hospital between 2015 and 2017. The SPADI questionnaire was completed by 349 participants. Not all participants' medical records provided the required demographic and clinical data.

Statistical analysis:

Data was analysed using STATA 14.0 (College Station, Texas, USA). Demographic and clinical data were described by summary statistics, where categorical variables (race and tumour grade) were reported in frequencies and percentages and numerical variables (age, time since surgery and nodes affected) were described by the mean and standard deviation.

Pain and disability were categorised into four categories according to scores from the SPADI questionnaire where 0 depicts 'no pain/no disability', 1-30 'mild pain/mild disability', 31-50 'moderate pain/moderate disability' and $>50$ 'severe pain/severe disability', respectively. Ordinal logistic regression was used for determining the association(s) between pain and disability scores with covariates, such as baseline demographics and treatment type. Ordinal logistic regression was used due to the presence of several ordered categories of the outcomes, pain and disability. Potential confounders and interacting variables were considered in the analysis. In the univariable analysis, odds ratios (OR) and 95\% confidence intervals (CIs) were calculated to summarize the effect of each covariate on pain and disability outcomes. Covariates with a p-value $<0.2$ in the univariate analysis were selected for consideration in the 
multivariable model. A backward selection procedure was used to investigate the most significant predictors of pain and disability scores in the multivariable analysis. The final model was presented by the OR and $95 \%$ CI for the OR of the predictor. A p value of $<0.05$ was considered statistically significant. The proportional odds assumption was investigated for the final model.

\section{Ethical Considerations}

Ethical clearance for this study was granted by the University of Cape Town Human Research Ethics Committee (approval number: 317/2017). This study was conducted in accordance with the Declaration of Helsinki (last updated in 2013) and International guidelines for Good Clinical Practice (ICH 1997).

\section{Results}

Demographic and clinical characteristics are summarised in Table 1. The majority of patients were of mixed ancestry (77\%) with the remainder Black African (14\%) and Caucasian (7\%). Age ranged from $34-84$ years, with a mean (standard deviation [SD]) of 60 (10.32) years. Follow-up was on average 6 and a half years (SD 2.43) since surgery, with a minimum of 2 years and maximum of 17 years. Slightly more participants had left affected side compared to right $(51 \%$ vs. $44 \%$; $>0.05)$. More patients had tumour grade II $(43 \%)$ compared to tumour grades I (18\%) and III (19\%), and the majority of patients had also received additional treatments such as chemotherapy (72\%), hormonal therapy (70\%) and radiotherapy 
(63\%), respectively. The large majority of patients underwent ALND compared to SNB (78\% vs. 13\%). There were no radical mastectomies, but $70 \%$ modified radical mastectomy (MRM) and 18\% wide local excision (WLE). Many patients received a combination of treatment modalities, including $88 \%$ who received both MRM and chemotherapy.

Table 1. Participant Demographic and Clinical Characteristics

\begin{tabular}{|c|c|c|}
\hline Variable & Number of Participants & \% or Mean (SD) \\
\hline \multicolumn{3}{|l|}{ Race $(N=349)$} \\
\hline Black African & 50 & 14.33 \\
\hline Caucasian & 24 & 6.88 \\
\hline Mixed ancestry & 269 & 77.08 \\
\hline Missing & 6 & 1.72 \\
\hline Age (years) & 333 & $60.05(10.32)$ \\
\hline \multicolumn{3}{|l|}{ Affected side ( $N=349)$} \\
\hline Left & 179 & 51.29 \\
\hline Right & 155 & 44.41 \\
\hline Missing & 15 & 4.30 \\
\hline \multicolumn{3}{|l|}{ Tumour grade $(\mathrm{N}=349)$} \\
\hline 1 & 66 & 18.91 \\
\hline 2 & 153 & 43.84 \\
\hline 3 & 68 & 19.48 \\
\hline Missing & 62 & 17.77 \\
\hline Number of nodes affected & 292 & $10.37(5.98)$ \\
\hline Duration since surgery (years) & 321 & $6.52(2.43)$ \\
\hline \multicolumn{3}{|l|}{ Surgery type $(\mathrm{N}=349)$} \\
\hline MRM & 256 & 73.35 \\
\hline WLE & 64 & 18.34 \\
\hline Missing & 29 & 8.31 \\
\hline \multicolumn{3}{|l|}{ Axillary Surgery $(\mathrm{N}=349)$} \\
\hline SNB & 46 & 13.18 \\
\hline ALND & 273 & 78.23 \\
\hline Missing & 30 & 8.60 \\
\hline
\end{tabular}




\begin{tabular}{|lcc|} 
Yes & 254 & 72.78 \\
No & 37 & 10.60 \\
Missing & 58 & 16.62 \\
Hormonal therapy $(\mathbf{N}=\mathbf{3 4 9})$ & & \\
$\quad$ Yes & 246 & 70.49 \\
No & 43 & 12.32 \\
Missing & 60 & 17.19 \\
Radiotherapy $(\mathbf{N}=\mathbf{3 4 9})$ & & \\
$\quad$ Yes & 221 & 63.32 \\
No & 120 & 34.48 \\
Missing & 8 & 2.29 \\
MRM + radiotherapy & 147 & 57.65 \\
WLE + radiotherapy & 60 & 95.24 \\
MRM + chemotherapy & 199 & 88.44 \\
WLE + chemotherapy & 41 & 78.85 \\
\hline
\end{tabular}

$\mathrm{SD}=$ Standard Deviation

MRM = Modified Radical Mastectomy

WLE $=$ Wide Local Excision

A summary of the SPADI results are presented in Table 2, according to individual items and total scores for pain and disability, respectively. Overall, the prevalence of shoulder morbidity in this population was $75 \%$ with only a quarter of patients reporting no pain or disability (a score of 0 ). When considered according to severity grading, half the patients had mild total SPADI scores, a quarter reported no pain or disability, and moderate and severe collectively accounted for the remaining quarter. There was a significant difference between total SPADI score when comparing the proportion who reported mild versus the proportion who reported moderate $(\mathrm{p}<0.001)$ whereas there was no significant difference between the proportion who reported moderate versus the proportion who reported severe SPADI scores $(\mathrm{p}=0.13)$.

When evaluating the congruence between pain and disability, $26 \%$ had no pain and $38 \%$ had no disability, whereas $14 \%$ had severe pain and $7 \%$ severe disability. Overall, more pain is present relative to disability. Similarly, as seen in Figure 1, there is not a complete association 
between all categories of pain and disability. In those with severe disability, a large proportion also had severe pain. However, in those with mild disability, although the large majority also had mild pain - many also reported both moderate and severe pain. Similarly, moderate disability comprised of both moderate and severe pain. The Pearson's correlation coefficient between pain and disability scores was 0.82 showing a strong linear relationship between pain and disability.

As seen in the individual components of pain and disability in Table 2, 74\% of patients experienced some degree of pain (similar to the overall shoulder morbidity of $75 \%$ ) whereas $63 \%$ experienced some level of disability. Mild pain was experienced by $46 \%$ of patients, and moderate and severe pain by $14 \%$ of patients, respectively. Mild disability was experienced by $53 \%$ of patients, moderate by $13 \%$, and severe disability by $9 \%$ of patients.

Table 2. Summary of SPADI scores according to severity; N (\%)

\begin{tabular}{|lcccc|}
\hline Pain & $\begin{array}{c}\text { None } \\
\text { N (\%) }\end{array}$ & $\begin{array}{c}\text { Mild } \\
\text { N }(\%)\end{array}$ & $\begin{array}{c}\text { Moderate } \\
\text { N (\%) }\end{array}$ & $\begin{array}{c}\text { Severe } \\
\text { N (\%) }\end{array}$ \\
\cline { 2 - 5 } At its worst & $86(27)$ & $75(24)$ & $51(16)$ & $103(33)$ \\
Lying on involved side & $169(53)$ & $60(19)$ & $42(13)$ & $50(15)$ \\
Reaching on a high shelf & $165(51)$ & $85(27)$ & $28(9)$ & $43(13)$ \\
$\begin{array}{l}\text { Touching the back of your } \\
\text { neck }\end{array}$ & $86(53)$ & $31(19)$ & $17(11)$ & $27(17)$ \\
$\begin{array}{l}\text { Pushing with the involved } \\
\text { arm }\end{array}$ & $210(66)$ & $44(14)$ & $27(8)$ & $38(12)$ \\
Pain Total & $83(26)$ & $145(46)$ & $45(14)$ & $44(14)$ \\
\hline Disability & $\mathbf{N o n e}$ & $\mathbf{M i l d}$ & Moderate & Severe \\
Washing your hair & $268(83)$ & $21(7)$ & $14(4)$ & $18(6)$ \\
Washing your back & $216(68)$ & $27(8)$ & $25(8)$ & $51(16)$ \\
$\begin{array}{l}\text { Putting on an undershirt } \\
\text { or pulling on a sweater }\end{array}$ & $264(83)$ & $19(6)$ & $10(3)$ & $27(8)$ \\
$\begin{array}{l}\text { Putting on a shirt on with } \\
\text { buttons down the front }\end{array}$ & $300(93)$ & $11(3)$ & $4(1)$ & $6(2)$ \\
Putting on your pants & $284(88)$ & $16(5)$ & $7(2)$ & $14(4)$ \\
\end{tabular}


Placing an object on a high shelf

$202(63)$

$$
48(15)
$$

Carrying a heavy object of $4.5 \mathrm{~kg}$ $152(47)$

$34(11)$

Removing something from your back pocket $268(84)$

Ranking scale for severity grading:

For Total Pain, Disability, and SPADI:

None: score of zero

Mild: score of 1-30

Moderate: score of 31-50

Severe: score $>50$
For Pain and Disability individual questions:

None: score of zero

Mild: score of 1-3

Moderate: score of $3-5$

Severe: score $>5$

Figure 1: Stacked Bar Chart showing the association between Categories of SPADI Pain and Disability

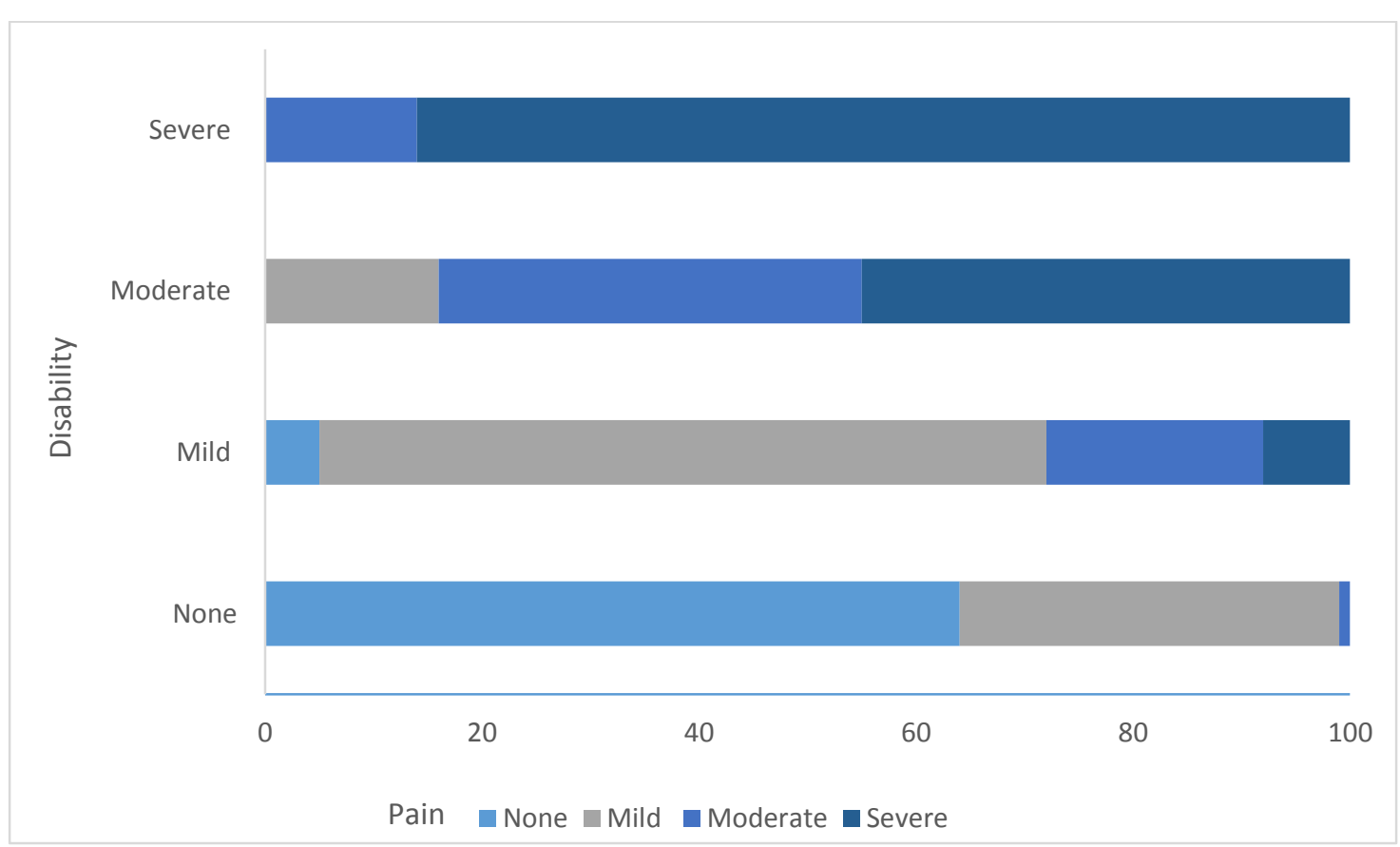

Table 3 and Table 4 summarize the results from univariable and multivariable ordinal logistic regression with respect to pain (Table 3) and disability (Table 4). Pain and disability, were 
ranked on an ordinal scale as none, mild, moderate and severe. The odds ratio is interpreted as the increase in odds of being in a higher pain or disability category per unit increase in the risk factor. The proportional odds assumptions was met for the final models of both pain and disability.

Utilizing univariable ordinal logistic regression analysis, variables associated with pain in this population group (all $\mathrm{p}<0.2$ ) were: race, the affected side of the primary tumour, total number of nodes affected, use of chemotherapy as an additional treatment modality, age, use of radiotherapy as an additional treatment modality, and axillary surgery (Table 3). In the multivariable ordinal logistic regression analysis, race, side, axillary surgery, chemotherapy and age remained as the most significant predictors of pain, whereas radiotherapy was no longer significant.

As seen in Table 3, Caucasian and mixed ancestry patients experienced less pain compared to Black African patients, but this OR was not statistically significant for mixed ancestry patients (Caucasian: OR 0.21; 95\% CI $0.05-0.82, \mathrm{p}=0.024$ and mixed ancestry: OR 0.54; 95\% CI $0.22-1.37, \mathrm{p}=0.194)$. Those patients who had the left side affected had 3.2 times increased odds of being in worse pain $(\mathrm{OR} 3.22 ; 95 \%$ CI $0.97-10, \mathrm{p}=0.056)$ compared with patients who had their right side affected. For each unit increase in age there was a corresponding $5 \%$ reduction in the odds of being in a higher pain category (OR $0.95 ; 95 \% \mathrm{CI}$ $0.93-0.98, \mathrm{p}<0.0001)$. The lack of chemotherapy as an additional treatment was associated with a $61 \%$ reduction in the odds of pain (OR 0.39; 95\% CI 0.18-0.83, $\mathrm{p}=0.015)$. ALND was associated with a reduced odds of being in a higher pain category by $52 \%$ (OR $0.48 ; 95 \% \mathrm{CI}$ $0.23-0.98, \mathrm{p}=0.044)$ 
To directly test the hypothesis that the side effect may differ by race, an overall model was constructed that included the covariates described, and an interaction term for race and side. Both the covariates remained significantly associated with higher pain, as did the interaction term for Caucasian when compared to the reference group of Black African $(\mathrm{p}=0.034)$, but not for mixed ancestry when compared to the reference group of Black African $(\mathrm{p}=0.156)$. Exploratory analysis of additional interaction terms showed no significant association with the outcome.

Covariates found to be correlated with disability in univariable ordinal logistic regression analysis included race, chemotherapy, age, radiotherapy and axillary surgery (Table 4). In the multivariable logistic regression analysis, chemotherapy was the only one that remained as a significant predictors of disability, after adjustment. The lack of exposure to chemotherapy as an additional treatment modality was associated with a $63 \%$ reduction in the odds of experiencing a worse category of disability (OR 0.37, 95\% CI $0.18-0.77, \mathrm{p}=$ $0.007)$.

Table 3: Ordinal Logistic Regression for Pain Categories

\begin{tabular}{|c|c|c|}
\hline & $\begin{array}{c}\text { Univariable } \\
\text { OR }(95 \% \mathrm{CI})\end{array}$ & $\begin{array}{c}\text { Multivariable } \\
\text { OR }(95 \% \text { CI })\end{array}$ \\
\hline $\begin{array}{l}\text { Race } \\
\text { Black African } \\
\text { (Reference) }\end{array}$ & & \\
\hline $\begin{array}{l}\text { Caucasian } \\
\text { Mixed ancestry }\end{array}$ & $\begin{array}{l}0.46(0.18,1.18) \\
0.49(0.28,0.88)\end{array}$ & $\begin{array}{c}0.21(0.05-0.82)^{*} \\
0.54(0.22-1.37)\end{array}$ \\
\hline Right Side & $0.77(0.51,1.17)$ & $0.31(0.10-1.03) *$ \\
\hline $\begin{array}{l}\text { Tumour Grade } \\
1 \text { (Reference) } \\
2 \\
3\end{array}$ & $\begin{array}{l}1.27(0.73,2.20) \\
1.30(0.68,2.48)\end{array}$ & \\
\hline Total nodes & $0.98(0.94,1.01)$ & \\
\hline
\end{tabular}




$\begin{array}{|lcc|}\text { No Chemotherapy } & 0.35(0.17,0.72) & 0.39(0.18,0.83)^{*} \\ \text { No Hormonal Therapy } & 0.97(0.53,1.77) & \\ \text { Date of Surgery } & 1.00(0.99,1.00) & \\ \text { Radiotherapy } & 1.60(1.03,2.48) & \\ \text { Age } & 0.95(0.92,0.98) & 0.95(0.93-0.98)^{* *} \\ \text { Surgery Type } & & \\ \quad \text { MRM (Reference) } & & \\ \quad \text { WLE } & 1.10(0.65,1.88) & \\ & & \\ \text { Axillary Surgery } & & \\ \quad \text { SNB (Reference) } & & \\ \quad \text { ALND } & 0.64(0.35,1.16) & \\ \text { Interaction of Race and } & & \\ \text { Side } & & \\ \quad \text { Caucasian } & 0.14(0.04,0.49) & \\ \quad \text { Mixed ancestry } & 0.26(0.11,0.58) & \\ \quad \text { Right side } & 0.24(0.08,0.72) & \\ \text { Caucasian/right } & 13.81(1.96,97.47) & \\ \quad \text { Mixed ancestry/right } & 3.57(1.07,11.88) & \\ & & \\ & & \end{array}$

MRM $=$ Modified Radical Mastectomy

$* \mathrm{p}<0.05, * * \mathrm{p}<0.01$

Table 4: Ordinal Logistic Regression for Disability Categories

\begin{tabular}{|c|c|c|}
\hline & $\begin{array}{l}\text { Univariable } \\
\text { OR }(95 \% \mathrm{CI})\end{array}$ & $\begin{array}{c}\text { Multivariable } \\
\text { OR }(95 \% \mathrm{CI})\end{array}$ \\
\hline $\begin{array}{l}\text { Race } \\
\quad \text { Black African } \\
\text { (Reference) }\end{array}$ & & \\
\hline Caucasian & $0.35(0.14,0.88)$ & \\
\hline Mixed ancestry & $0.55(0.31,0.97)$ & \\
\hline Right Side & $0.86(0.57,1.31)$ & \\
\hline $\begin{array}{r}\text { Tumour Grade } \\
1 \text { (Reference) }\end{array}$ & & \\
\hline 2 & $1.13(0.64,1.98)$ & \\
\hline 3 & $1.33(0.69,2.58)$ & \\
\hline Total nodes & $0.99(0.96,1.03)$ & \\
\hline No Chemotherapy & $0.37(0.18,0.77)$ & $0.37(0.18-0.77)^{* *}$ \\
\hline No Hormonal Therapy & $1.21(0.65,2.23)$ & \\
\hline
\end{tabular}




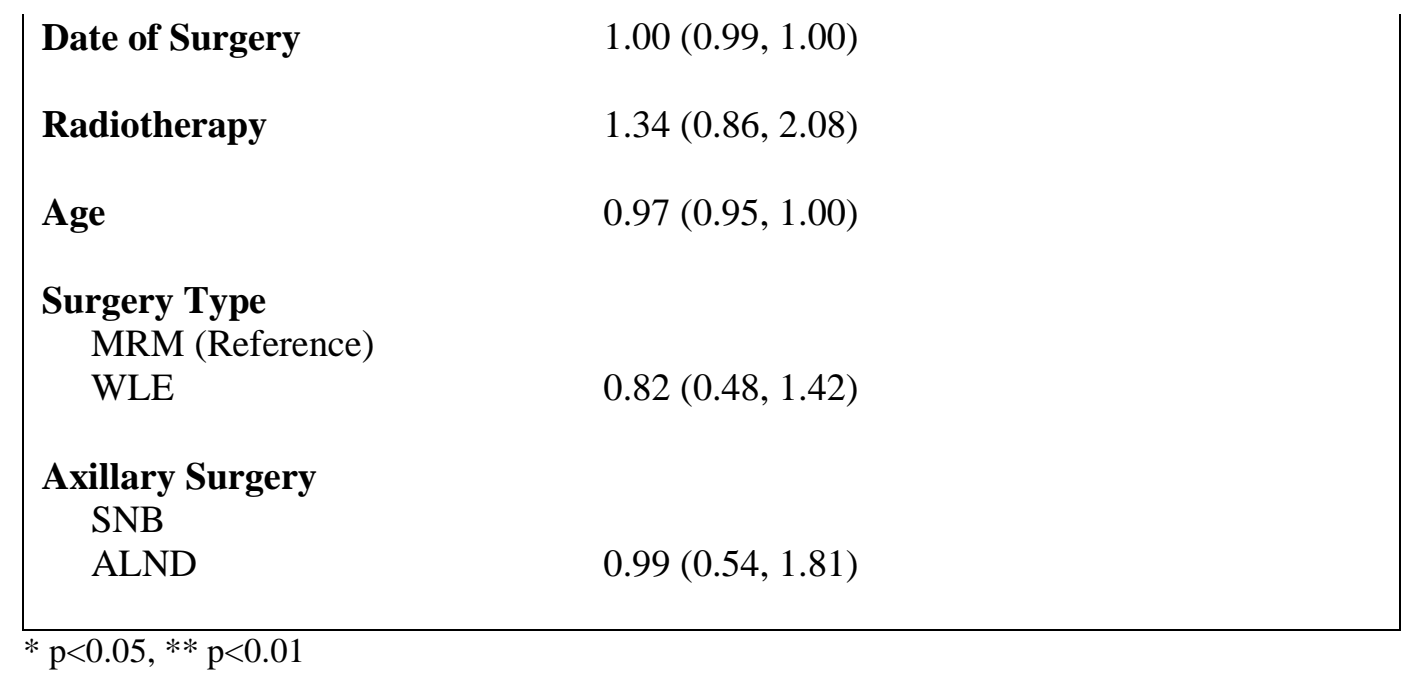

\section{Discussion}

This analysis reports on a group of individuals in a LMIC state-provided facility in Cape Town, South Africa. Approximately 600 new patients and many more follow-ups are seen annually at this large, tertiary academic breast cancer clinic, from a broad range of referral centres within Cape Town. On average, patients were 6.52 years post-surgery when they were enrolled into this study, with a minimum of 2.37 years and a maximum of 17.5 years, representing long-term outcome data post-surgery for breast cancer. This is a similar finding to previous work from an author in this group from a European population group showing that pain continues to persistent 6 years after treatment (Shamley et al. 2012). This similarity exists in the presence of a large number of radical mastectomies in this patient group compared to those in the European study (Shamley et al. 2012).

A total of $75 \%$ of patients experienced some level of pain and disability, with $25 \%$ experiencing none at all. The overall percentage was almost identical for both total SPADI score and the domain of pain scores ( $75 \%$ and $74 \%$, respectively), whereas the disability score was somewhat less with $63 \%$ experiencing mild, moderate or severe disability. These figures represent a significant burden of long-term morbidity. The reduced prevalence of 
disability compared to pain indicates that pain may be the more significant burden of shoulder morbidity, accompanied by disability in the large majority. According to overall SPADI score, $53 \%$ of patients were mild, $13 \%$ moderate, and $9 \%$ severe, respectively. The proportion of patients in each group of overall SPADI score was statistically significantly different when comparing mild versus moderate groups, but not for moderate versus severe groups, respectively. Mild pain and disability accounts for the largest group; $46 \%$ of patients in each of the domains. Differences lie between pain and disability in the moderate and severe groups, suggesting that more pain exists but not necessarily in the presence of accompanying disability.

Separate ordinal logistic regression models were constructed for pain and disability due to the differing burden each one represents, as seen from Table 2 and Figure 1. The proportional odds assumptions were met for the final multivariable ordinal regression models of pain and disability, confirming the ORs increase at a consistent proportion in the model. Whereas age, side affected, chemotherapy, axillary surgery and race were risk factors for pain, only the use of chemotherapy was a risk factor for disability.

Black African patients had a greater odds of being in the higher pain categories, when compared to Caucasian and mixed ancestry patients. We are aware of differences existing between racial groups indicating that Black patients are at a higher risk, although this is largely from the African-American population (Dean et al. 2015; Blinder \& Griggs 2013). Differences between the racial groups may exist due to cultural approaches to treatmentseeking behaviours, delays in seeking or accessing treatment and socioeconomic status (SES). The prevalence of obesity is often higher in the Black population, particularly Black women (Hendley et al. 2011) and given high BMI is a known risk factor for shoulder 
morbidity (Hidding et al. 2014), one needs to consider the presence of obesity in Black patients as a mediator of pain (Dean et al. 2015). Mediation analysis has suggested that BMI can attenuate the association between race and disability by $40 \%$ (Dean et al. 2015). However, as this was not measured in our study, we cannot make inferences regarding it. This is a public sector hospital and therefore patients seen are generally at a lower SES, which in addition to being of Black African race, may be associated with presenting with more advanced disease and receiving fewer treatment options (Dean et al. 2015; Smoot et al. 2016; Blinder \& Griggs 2013). 40\% of patients presented with grade II tumours, although $18 \%$ had missing data for this variable. A recent study at this breast cancer facility found that $78 \%$ of women were unemployed despite having received treatment more than 2 years prior (personal communication). It is important to note that more than $70 \%$ of the patients included in the group were of mixed ancestry. This is not reflective of the South African population where the largest racial group is Black African, however, it is representative of the Cape Town region where mixed ancestry is the largest population group (Anon 2014).

In this study, the mean age was 60 years, ranging from 34 to 83 years. Increasing age was statistically significantly associated with reduced pain, with an OR of 0.95 (95\% CI 0.93 0.98, $\mathrm{p}<0.0001)$. Older age is a risk factor for reduced ROM and limitation in ADL, however, younger age is associated with reduced muscle strength (Hidding et al. 2014). This discrepancy may be due to younger patients being more sensitive to the discomfort resulting from axillary surgery or having different expectations (Fleissig et al. 2006). A study with a relatively similar population age group to ours (mean age of patients were 56 years) found age to be a strong predictor of long-term shoulder-arm function (Kootstra et al. 2013). Liu et al. (Liu et al. 2009) concluded that younger age was a strong predictor of late morbidity, 
which correlates with our finding that the younger you are, the worse your pain, particularly in our group of long-term follow up patients.

When considering side affected, there was a relatively even split of left and right side affected, with slightly more left affected. Left side affected was associated with a higher risk of pain, which corroborates what has been shown previously. It is well understood that left affected side represents a higher risk group for development of pain and disability (Shamley et al. 2009). A number of other studies have also reported increased frequency of pain on the left side (Shamley et al. 2012; Shamley et al. 2007).

Chemotherapy treatment was associated with a 37\% increased odds of having a worse disability score and $39 \%$ of having a worse pain score. Chemotherapy has been linked to increased upper limb pain and dysfunction and lymphoedema (Shamley 2015; Gosselink et al. 2003; Hidding et al. 2014), although has also been shown to reduce the odds of reduced ROM reduction when compared with not receiving chemotherapy (Hidding et al. 2014). Further analysis was not able to be conducted related to the specific type of chemotherapy received, how many cycles were received and whether it was as adjuvant or neoadjuvant therapy, respectively. ALND was associated with reduced pain when compared to SNB. This is a surprising finding given most of the evidence suggests that SNB has more favourable outcome in terms of shoulder morbidity (De Groef et al. 2016; Hidding et al. 2014). A similar proportion of patients in both groups received hormonal treatment, radiotherapy and chemotherapy. Furthermore, more patients in the ALND groups also had left side affected (57\% ALND vs. $33 \%$ SNB). Many patients had received additional treatments with chemotherapy (70\%), radiotherapy (63\%), and hormonal treatment (70\%). Given radiotherapy result in long-term morbidities, including diminished tissue healing or increased 
tissue fibrosis, perhaps this provides evidence of shoulder morbidity being less related to type of axillary surgery only, but rather the additional other treatments (Gosselink et al. 2003).

The SPADI questionnaire was used as it is quick and easy to complete (Torres-Lacomba et al. 2015). It has also been shown to have high reliability and validity (Roach et al. 1991) and is able to identify key functional limitations in breast cancer survivors, making it a useful tool for identification of patients at risk of developing shoulder pain and disability (Shamley 2015). It has not be validated in a South African population, however, a study evaluated the concurrent validity, construct validity and the test-retest reliability of a Face-SPADI in South African breast cancer survivors, and showed excellent concurrent validity, internal consistency and test-retest reliability (personal communication). Thus we can be confident of the results of this study which utilised the SPADI numerical questionnaire.

There are several limitations to this study. There is a proportion of missing demographic and clinical data, particularly with respect to tumour grade, surgical techniques employed and the use of chemotherapy and hormonal treatment. This may affect some of the statistical analysis with regards to regression in terms of sample size and confidence intervals. Although 10 patients did not fully complete the SPADI questionnaire, the questionnaire makes adjustment for this in the calculation. Although internal validity is likely to be high, there is limited external generalizability. However, this study was aimed at providing data for a specific groups of patients in a LMIC. No patients in this group underwent a radical mastectomy, as this is not the clinical treatment pathway of this hospital. We are aware that radical mastectomy is a risk factor for shoulder morbidity so perhaps this may underrepresent the burden. The SPADI questionnaire requires self-reporting of pain and disability, introducing the challenges of subjective reporting and self-perceived outcomes. However, as discussed 
above, SPADI has been shown to be reliable and valid, and has frequently been employed in research settings for assessment of shoulder dysfunction.

The fact that this data shows such a significant burden of shoulder morbidity 6 years after treatment highlights the importance of long-term surveillance and rehabilitation. There is a clear need for prospective surveillance programmes that can be integrated into survivorship programmes, particularly within South Africa and other LMICs (Shamley \& Robb 2015; Hidding et al. 2014). The ability to identify those patients at risk of long-term morbidity reduces the need for intensive rehabilitation and those associated costs (Shamley \& Robb 2015). Physiotherapy and exercise are able offer support for these problems (McNeely et al. 2010), however, there are insufficient resources to provide these for each cancer patient routinely and therefore there is a need to identify and target resources, particularly in a country such as South Africa where resources are limited. This has an economic public health burden in that many of these women require to contribute to their households in order to feed and house their families. Oftentimes, these women work in jobs that require a high level of physical functioning, and thus the inability to move one's shoulder represents a significant barrier to return to work. Rehabilitation would reduce the public health burden in an alreadyburdened service and public health sector facility. Having key baseline data and predictors enables us to design and implement care pathways for those patients at risk. A greater focus needs to be given to survivorship strategies, surveillance and early intervention warning systems as part of an integrated cancer care model.

\section{Funding and Declaration of Interest}


The authors report no conflicts of interest. The authors alone are responsible for the content and writing of the paper.

Funding for publication was publication via an NRF grant (RRR Grant 93541). 


\section{References}

Anon, 2014. Race, Ethnicity and Language in South Africa | World Elections. Available at: https://welections.wordpress.com/guide-to-the-2014-south-african-election/raceethnicity-and-language-in-south-africa/ [Accessed September 18, 2017].

Anon, The Disabilities of the Arm, Shoulder and Hand (DASH) Outcome Measure. Available at: http://www.dash.iwh.on.ca/about-dash [Accessed July 25, 2017].

Blinder, V.S. \& Griggs, J.J., 2013. Health disparities and the cancer survivor. Seminars in Oncology, 40(6), pp.796-803. Available at: http://dx.doi.org/10.1053/j.seminoncol.2013.09.003.

Bodai, B.I. \& Tuso, P., 2015. Breast cancer survivorship: a comprehensive review of longterm medical issues and lifestyle recommendations. The Permanente journal, 19(2), pp.48-79.

Borstad, J.D. \& Szucs, K.A., 2012. Three-dimensional scapula kinematics and shoulder function examined before and after surgical treatment for breast cancer. Human Movement Science, 31(2), pp.408-418.

Breckenridge, J.D. \& McAuley, J.H., 2011. Shoulder Pain and Disability Index (SPADI). Journal of Physiotherapy, 57(3), p.197.

Cantarero-Villanueva, I. et al., 2011. Associations among musculoskeletal impairments, depression, body image and fatigue in breast cancer survivors within the first year after treatment. European Journal of Cancer Care, 20(5), pp.632-639.

Cotlar, A.M., Dubose, J.J. \& Rose, D.M., 2003. History of surgery for breast cancer: Radical to the sublime. Current Surgery, 60(3), pp.329-337.

Dawson, J. et al., 2009. The Oxford shoulder score revisited. Archives of Orthopaedic and Trauma Surgery, 129(1), pp.119-123.

Dean, L. et al., 2015. Black Breast Cancer Survivors Experience Greater Upper Extremity 
Disability. Breast Cancer Res Treat, 154(1), pp.117-125.

Fleissig, A. et al., 2006. Post-operative arm morbidity and quality of life. Results of the ALMANAC randomised trial comparing sentinel node biopsy with standard axillary treatment in the management of patients with early breast cancer. Breast Cancer Research and Treatment, 95(3), pp.279-293.

Freitas-Silva, R. et al., 2010. Comparison of quality of life, satisfaction with surgery and shoulder-arm morbidity in breast cancer survivors submitted to breast-conserving therapy or mastectomy followed by immediate breast reconstruction. Clinics, 65(8), pp.781-787.

Gosselink, R. et al., 2003. Recovery of upper limb function after axillary dissection. Journal of Surgical Oncology, 83(4), pp.204-211.

Gritsenko, V. et al., 2015. Feasibility of using low-cost motion capture for automated screening of shoulder motion limitation after breast cancer surgery. PLoS ONE, 10(6), pp.1-9.

De Groef, A. et al., 2016. Arm lymphoedema and upper limb impairments in sentinel nodenegative breast cancer patients: A one year follow-up study. The Breast, 29, pp.102108.

Harrington, S. et al., 2011. Comparison of shoulder flexibility, strength, and function between breast cancer survivors and healthy participants. Journal of Cancer Survivorship, 5(2), pp.167-174.

Hayes, S.C. et al., 2010. Upper-body morbidity following breast cancer treatment is common, may persist longer-term and adversely influences quality of life. Health and Quality of Life Outcomes, 8(1), p.92.

Van Der Heijden, G.J.M.G., Leffers, P. \& Bouter, L.M., 2000. Shoulder disability questionnaire design and responsiveness of a functional status measure. Journal of 
Clinical Epidemiology, 53(1), pp.29-38.

Helms, G. et al., 2009. Shoulder-arm morbidity in patients with sentinel node biopsy and complete axillary dissection - data from a prospective randomised trial. The Journal of Cancer Surgery, 35, pp.696-701.

Hendley, Y. et al., 2011. Differences in Weight Perception Among Blacks and Whites. Journal of Women's Health, 20(12), pp.1805-1811. Available at: http://www.liebertonline.com/doi/abs/10.1089/jwh.2010.2262.

Herbst, M.C., 2016. Cancer Association of South Africa (CANSA) Fact Sheet on the Incidence of Cancer Among Females from 2000 to 2011,

Hidding, J.T. et al., 2014. Treatment related impairments in arm and shoulder in patients with breast cancer: A systematic review. PLoS ONE, 9(5).

Hopwood, P. et al., 2010. Comparison of patient-reported breast, arm, and shoulder symptoms and body image after radiotherapy for early breast cancer: 5-year follow-up in the randomised Standardisation of Breast Radiotherapy (START) trials. The Lancet Oncology, 11(3), pp.231-240.

Hudak, P., Amadio, P. \& Bombardier, C., 1996. Development of an upper extremity outcome measure: the DASH (disabilities of the arm, shoulder and hand) The Upper Extremity Collaborative Group (UECG). Am J Ind Med, 30(3), p.372.

International Agency for Research on Cancer (IARC), Globocan 2012: Estimated Cancer Incidence, Mortality and Prevalence Worldwide in 2012. Available at: http://globocan.iarc.fr/Pages/fact_sheets_population.aspx [Accessed February 24, 2017].

Jemal, A., Bray, F. \& Ferlay, J., 2011. Global Cancer Statistics: 2011. CA Cancer J Clin, 61, pp.69-90.

Johansen, S. et al., 2014. Arm and shoulder morbidity following surgery and radiotherapy for breast cancer. Acta Oncologica, 53(4), pp.521-529. 
Koehler, L.A. et al., 2015. Movement, Function, Pain, and Postoperative Edema in Axillary Web Syndrome. Phys Ther., 95(10), pp.1345-1353.

Kootstra, J.J. et al., 2013. A longitudinal study of shoulder and arm morbidity in breast cancer survivors 7 years after sentinel lymph node biopsy or axillary lymph node dissection. Breast Cancer Research and Treatment, 139(1), pp.125-134.

Langford, D.J. et al., 2014. Persistent arm pain is distinct from persistent breast pain following breast cancer surgery. Journal of Pain, 15(12), pp.1238-1247.

LeBlanc, M. et al., 2014. Validation of quick DASH outcome measure in breast cancer survivors for upper extremity disability. Arch Phys Med Rehabil, 95(3), pp.493-498.

Levangie, P.K. \& Drouin, J., 2009. Magnitude of late effects of breast cancer treatments on shoulder function: A systematic review. Breast Cancer Research and Treatment, 116(1), pp.1-15.

Levy, E.W. et al., 2012. Predictors of functional shoulder recovery at 1 and 12 months after breast cancer surgery. Breast Cancer Research and Treatment, 134(1), pp.315-324.

Liu, C. et al., 2009. Late morbidity associated with a tumour-negative sentinel lymph node biopsy in primary breast cancer patients: a systematic review. European journal of cancer, 45(9), pp.1560-1568. Available at: http://dx.doi.org/10.1016/j.ejca.2009.02.012.

Mansel, R.E. et al., 2006. Randomized multicenter trial of sentinel node biopsy versus standard axillary treatment in operable breast cancer: The ALMANAC trial. Journal of the National Cancer Institute, 98(9), pp.599-609.

Marcus, T.S., Lunda, S. \& Fernandez, L., 2013. Delayed breast cancer presentation: Hospital data should inform proactive primary care. African Journal of Primary Health Care and Family Medicine, 5(1), pp.1-7.

McNeely, M.L. et al., 2010. Exercise interventions for upper-limb dysfunction due to breast cancer treatment. Cochrane database of systematic reviews (Online), (6), p.CD005211. 
Miaskowski, C. et al., 2014. Identification of patient subgroups and risk factors for persistent arm/shoulder pain following breast cancer surgery. European Journal of Oncology Nursing, 18(3), pp.242-253.

Monleon, S. et al., 2016. Shoulder Strength Changes One Year After Axillary Lymph Node Dissection or Sentinel Lymph Node Biopsy in Patients With Breast Cancer. Archives of Physical Medicine and Rehabilitation, 97(6), pp.953-963.

Mutebi, M. \& Edge, J., 2014. Stigma, survivorship and solutions: Addressing the challenges of living with breast cancer in low-resource areas. South African Medical Journal, 104(5), pp.383-385.

National Health Laboratory Service, 2011. 2011 National Cancer Registry, Available at: http://www.cansa.org.za/south-african-cancer-statistics/.

Nesvold, I. et al., 2009. Arm and shoulder morbidity in breast cancer patients after breastconserving therapy versus mastectomy. , (June 2017).

Nesvold, I.L. et al., 2009. Kwan's arm problem scale: Psychometric examination in a sample of stage II breast cancer survivors. Breast Cancer Research and Treatment, 117(2), pp.281-288.

Paul, A. et al., 2004. A comparison of four shoulder-specific questionnaires in primary care. Annals of the rheumatic diseases, 63(10), pp.1293-9.

Peintinger, F. et al., 2003. Comparison of quality of life and arm complaints after axillary lymph node dissection vs sentinel lymph node biopsy in breast cancer patients. British Journal of Cancer, 89(4), pp.648-652.

Poggi, M.M. et al., 2003. Eighteen-year results in the treatment of early breast carcinoma with mastectomy versus breast conservation therapy: The National Cancer Institute randomized trial. Cancer, 98(4), pp.697-702.

Roach, K. et al., 1991. Development of a shoulder pain and disability index. Arthritis Care 
Res, 4(4), pp.143-9.

Roy, J.S., Macdermid, J.C. \& Woodhouse, L.J., 2009. Measuring shoulder function: A systematic review of four questionnaires. Arthritis Care and Research, 61(5), pp.623632.

Shamley, D., 2015. A Cross-Disciplinary Look at Shoulder Pain and Dysfunction after Treatment for Breast Cancer. Int J Cancer Clin Res, 1(9).

Shamley, D. et al., 2009. Three-dimensional scapulothoracic motion following treatment for breast cancer. Breast Cancer Research and Treatment, 118(2), pp.315-322.

Shamley, D., Lascurain-Aguirrebena, I. \& Oskrochi, R., 2014. Clinical Anatomy of the Shoulder After Treatment for Breast Cancer. Clinical Anatomy, 27, pp.467-477.

Shamley, D., Lascurain-aguirrebeña, I. \& Oskrochi, R., 2012. Shoulder morbidity after treatment for breast cancer is bilateral and greater after mastectomy. Acta Oncologica, 51(8), pp.1045-1053.

Shamley, D. \& Robb, K., 2015. An early warning surveillance programme for detecting upper limb deterioration after treatment for breast cancer : A novel technology supported system. BMC Cancer, pp.1-4.

Shamley, D.R. et al., 2007. Changes in shoulder muscle size and activity following treatment for breast cancer. Breast Cancer Research and Treatment, 106(1), pp.19-27.

Shamley, D.R. et al., 2005. Delayed versus immediate exercises following surgery for breast cancer: A systematic review. Breast Cancer Research and Treatment, 90(3), pp.263271.

Smoot, B. et al., 2016. Predictors of Altered Upper Extremity Function During the First Year After Breast Cancer Treatment. American Journal of Physical Medicine \& Rehabilitation, p.1.

Straub, J.M. et al., 2015. Radiation-induced fibrosis: mechanisms and implications for 
therapy. J Cancer Res Clin Oncol, 141(11), pp.1985-1994.

The American College of Obstetricians and Gynaecologists, 2017. Clinical Management Guidelines for Obstetrician - Gynecologists Breast Cancer Risk Assessment and Screening in Average-Risk Women., 130(122), pp.1-16.

Torres-Lacomba, M. et al., 2015. Spanish cultural adaptation and validation of the shoulder pain and disability index, and the oxford shoulder score after breast cancer surgery. Health and Quality of Life Outcomes, 13(1), p.63.

Tosello, G. et al., 2014. Breast surgery for metastatic breast cancer. Cochrane Database of Systematic Reviews, (9).

UpToDate, Breast cancer guide to diagnosis and treatment. Available at: https://www.uptodate.com/contents/breast-cancer-guide-to-diagnosis-and-treatmentbeyond-the-basics [Accessed February 26, 2017].

Williams, J., Holleman, D. \& Simel, D., 1995. Measuring shoulder function with the Shoulder Pain and Disability Index (SPADI). J Rheumatol, 22(4), p.1995.

Yeung, W.M., McPhail, S.M. \& Kuys, S.S., 2015. A systematic review of axillary web syndrome (AWS). Journal of Cancer Survivorship, 9(4), pp.576-598.

\section{PART D}




\section{APPENDICES}

1. SPADI Questionnaire

2. Ethics Approval Letter

3. Journal submission guidelines 


\section{Appendix 1: SPADI Questionnaire}

\section{Pain Scale}

How severe is your pain?

Circle the number that best describes your pain where: $\mathbf{0}=$ no pain at all and $\mathbf{1 0}=$ the worst pain imaginable

\begin{tabular}{|l|l|l|l|l|l|l|l|l|l|l|l|}
\hline 1.At its worst? & 0 & 1 & 2 & 3 & 4 & 5 & 6 & 7 & 8 & 9 & 10 \\
\hline 2.When lying on the involved side? & 0 & 1 & 2 & 3 & 4 & 5 & 6 & 7 & 8 & 9 & 10 \\
\hline 3.Reaching for something on a high shelf? & 0 & 1 & 2 & 3 & 4 & 5 & 6 & 7 & 8 & 9 & 10 \\
\hline 4.Touching the back of your neck? & 0 & 1 & 2 & 3 & 4 & 5 & 6 & 7 & 8 & 9 & 10 \\
\hline 5.Pushing with the involved arm? & 0 & 1 & 2 & 3 & 4 & 5 & 6 & 7 & 8 & 9 & 10 \\
\hline
\end{tabular}

\section{Disability Scale}

\section{How much difficulty do you have?}

Circle the number that best describes your experience where: $\mathbf{0}=$ no difficulty and $\mathbf{1 0}=$ so difficult it requires help

\begin{tabular}{|l|l|l|l|l|l|l|l|l|l|l|l|}
\hline 1.Washing your hair? & 0 & 1 & 2 & 3 & 4 & 5 & 6 & 7 & 8 & 9 & 10 \\
\hline 2.Washing your back? & 0 & 1 & 2 & 3 & 4 & 5 & 6 & 7 & 8 & 9 & 10 \\
\hline 3.Putting on an undershirt or jumper? & 0 & 1 & 2 & 3 & 4 & 5 & 6 & 7 & 8 & 9 & 10 \\
\hline $\begin{array}{l}\text { 4.Putting on a shirt that buttons down the } \\
\text { front? }\end{array}$ & 0 & 1 & 2 & 3 & 4 & 5 & 6 & 7 & 8 & 9 & 10 \\
\hline 5.Putting on your pants? & & & & & & & & & & & \\
\hline 6.Placing an object on a high shelf? & 0 & 1 & 2 & 3 & 4 & 5 & 6 & 7 & 8 & 9 & 10 \\
\hline 7.Carrying a heavy object of 10 pounds (4.5 & 0 & 1 & 2 & 3 & 4 & 5 & 6 & 7 & 8 & 9 & 10 \\
kilograms) & & & & & & & & & & & \\
\hline
\end{tabular}




\begin{tabular}{|l|l|l|l|l|l|l|l|l|l|l|l|}
\hline $\begin{array}{l}\text { 8.Removing something from your back } \\
\text { pocket? }\end{array}$ & 0 & 1 & 2 & 3 & 4 & 5 & 6 & 7 & 8 & 9 & 10 \\
\hline
\end{tabular}




\title{
Appendix 2: Ethics approval letter
}

\author{
UNIVERSITY OF CAPE TOWN \\ Faculty of Health Sciences \\ Human Research Ethlcs Committee
}

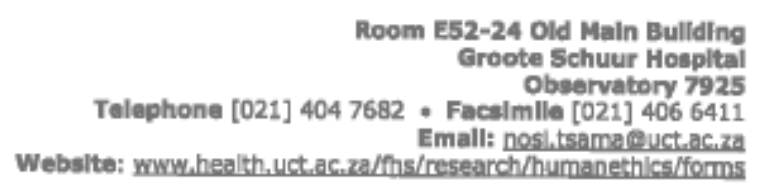

17 May 2017

HREC REF: 317/2017

Dr D shamley

Clinical Research Centre

L51, Old Main Building

Dear Dr Shamiey

PROJECT TITLE: PREVALENCE OF SHOULDER MORBIDITY AFTER TREATMENT FOR BREAST CANCER IN SOUTH AFRICA-(Masters' candldate-N Kramer) sub-study linked to 312/2012

Thank you for submitting your study to the Faculty of Health Sciences Human Research Ethics Committee for review.

It is a pleasure to Inform you that the HREC has formally approved the above-mentloned study.

Approval is granted for one year untll the 30th May 2018.

Please submit a progress form, using the standardlsed Annual Report Form If the study continues beyond the approval period. Please submit a Standard Closure form if the study is completed within the approval period.

(Forms can be found on our website: www.health.uct.ac.za/fhs/research/humanethics/forms)

We acknowledge that the following student will be involved in this study: Nicole Kramer

Please note that for all studies approved by the HREC, the princlpal Investigator must obtain appropriate institutional approval before the research may occur.

Please quote the HREC REF In all your correspondence.

Please note that the ongolng ethical conduct of the study remains the responslbility of the principal investigator.

Yours sincerely

RROFESSOR M BLOCKMAN

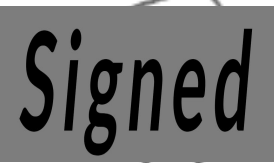

CHATRPERSON, FHS HUMAN RFSEARCH ETHTCS COMMTTEE

Federal Wide Assurance Number: FWA00001637.

Institutional Revlew Board (IRB) number: IRB00001938 


\section{Appendix 3: Acta Oncologica Journal Instructions for Authors}

(http://www.tandfonline.com/action/authorSubmission?journalCode=ionc20\&page=instructions)

\section{About the journal}

Acta Oncologica is an international, peer reviewed journal, publishing high-quality, original research. Please see the journal's Aims \& Scope for information about its focus and peerreview policy.

Please note that this journal only publishes manuscripts in English.

This journal accepts the following article types: original articles, reviews, letters, correspondence, technical notes and short communications.

\section{Peer review}

Taylor \& Francis is committed to peer-review integrity and upholding the highest standards of review. Once your paper has been assessed for suitability by the editor, it will then be single blind peer-reviewed by independent, anonymous expert referees. Find out more about what to expect during peer review and read our guidance on publishing ethics.

\section{Preparing your paper}

All authors submitting to medicine, biomedicine, health sciences, allied and public health journals should conform to the Uniform Requirements for Manuscripts Submitted to Biomedical Journals, prepared by the International Committee of Medical Journal Editors (ICMJE).

Structure

The text should, usually, be divided into the sections: Introduction, Material and Methods, Results, and Discussion.

Word limits

Please include a word count for your paper.

There are no word limits for articles in this journal.

Style guidelines

Please refer to these style guidelines when preparing your paper, rather than any published articles or a sample copy.

Please use British or American spelling style consistently throughout your manuscript. 
Please use single quotation marks, except where 'a quotation is "within" a quotation'. Please note that long quotations should be indented without quotation marks.

Abbreviations, which are not generally accepted, should be spelled out when first used in text. Uncommon abbreviations and clinical jargon should be avoided.

Footnotes are not accepted.

Formatting and templates

Papers may be submitted in any standard format, including Word. Figures should be saved separately from the text. To assist you in preparing your paper, we provide formatting templates.

Word templates are available for this journal. Please save the template to your hard drive, ready for use.

If you are not able to use the templates via the links (or if you have any other template queries) please contact authortemplate@tandf.co.uk

Please supply your manuscript typed with double spacing throughout the article (at least 1 $\mathrm{cm}$ between the lines) and margins of at least $4 \mathrm{~cm}$ on the left side and at the top.

1. Please be consistent. The same elements should be keyed in exactly the same way throughout the manuscript.

2. Do not break words at the end of lines. Use a hyphen only to hyphenate compound words.

3. Enter only one space after the full-stop at the end of a sentence.

4. When emphasizing words please use the italic feature of your word processor software.

5. Do not justify your text; use a ragged right-hand margin.

6. Use a double hyphen (--) to indicate a dash in text.

7. Do not use the lowercase I for 1 (one) or the uppercase $O$ for 0 (zero).

8. The space bar should only be used as a word separator. Use TAB when identifying paragraphs or separating columns in tables.

\section{Tables}

Type each table double-spaced on a separate page. Do not submit tables as photographs. Supply a brief title for each table. Give each column a short or abbreviated heading. Place explanatory matter in notes under the table, not in the heading.

\section{Please Note: Journal instructions require tables to be double spaced, however, tables have} been presented in dissertation with single spacing for ease of readability

\section{Illustrations}

Submit illustrations as separate files in TIFF or EPS format, and stored with an image resolution of at least 300 DPI (line figures preferably higher). Figure number should be indicated in the file name. Figure legends should be provided at the last page of the main text. Letters and numerals should be large enough to allow reduction of illustrations to onecolumn width $(8 \mathrm{~cm})$. Please indicate in Manuscript Central which of the figure images that 
you wish to print in colour in the journal, and acknowledge the printing costs for colour figures. The current rate is $\$ 200$ per article. This cost must be bourne by the author(s).

\section{References}

Please use this reference style guide when preparing your paper. An EndNote output style is also available to assist you.

Checklist: what to include

1. Author details. Please ensure everyone meeting the International Committee of Medical Journal Editors (ICMJE) requirements for authorship is included as an author of your paper.Please ensure everyone meeting the International Committee of Medical Journal Editors (ICJME) requirements for authorship is included as an author of your paper.Please include all authors' full names, affiliations, postal addresses, telephone numbers and email addresses on the title page. Where available, please also include ORCID identifiers and social media handles (Facebook, Twitter or LinkedIn). One author will need to be identified as the corresponding author, with their email address normally displayed in the article PDF (depending on the journal) and the online article. Authors' affiliations are the affiliations where the research was conducted. If any of the named co-authors moves affiliation during the peer-review process, the new affiliation can be given as a footnote. Please note that no changes to affiliation can be made after your paper is accepted. Read more on authorship.

2. A structured abstract of no more than 300 words. Abstracts should be structured and arranged according to the same headings that are used in the text; Background, Material and Methods, Results and Conclusion. An abstract is required for all manuscript types, except for 'Letters to the Editor' and other Read tips on writing your abstract.

3. Graphical abstract(Optional). This is an image to give readers a clear idea of the content of your article. It should be a maximum width of 525 pixels. If your image is narrower than 525 pixels, please place it on a white background 525 pixels wide to ensure the dimensions are maintained. Save the graphical abstract as a .jpg, .png, or .gif. Please do not embed it in the manuscript file but save it as a separate file, labelled GraphicalAbstract1.

4. You can opt to include a video abstract with your article. Find out how these can help your work reach a wider audience, and what to think about when filming.

5. 4-7 keywords. Read making your article more discoverable, including information on choosing a title and search engine optimization.

6. Funding details. Please supply all details required by your funding and grant-awarding bodies as follows:

For single agency grants: This work was supported by the[Funding Agency] under Grant [number xxxx].

For multiple agency grants: This work was supported by the [funding Agency 1]; under Grant [number xxxx]; [Funding Agency 2] under Grant [number xxxx]; and [Funding Agency 3] under Grant [number $x x x x$ ].

7. Disclosure statement. This is to acknowledge any financial interest or benefit that has arisen from the direct applications of your research. Further guidance on what is a conflict of interest and how to disclose it.

8. Supplemental online material. Supplemental material can be a video, dataset, fileset, sound file or anything which supports (and is pertinent to) your paper. We publish supplemental material online via Figshare. Find out more about supplemental material and how to submit it with your article.

9. Figures. Figures should be high quality ( $1200 \mathrm{dpi}$ for line art, $600 \mathrm{dpi}$ for grayscale and $300 \mathrm{dpi}$ for color, at the correct size). Figures should be saved as TIFF, PostScript or EPS files. More information on how to prepare artwork. 
10. Tables. Tables should present new information rather than duplicating what is in the text. Readers should be able to interpret the table without reference to the text. Please supply editable files.

11. Equations. If you are submitting your manuscript as a Word document, please ensure that equations are editable. More information about mathematical symbols and equations.

12. Units. Please use SI units (non-italicized).

\section{Using third-party material in your paper}

You must obtain the necessary permission to reuse third-party material in your article. The use of short extracts of text and some other types of material is usually permitted, on a limited basis, for the purposes of criticism and review without securing formal permission. If you wish to include any material in your paper for which you do not hold copyright, and which is not covered by this informal agreement, you will need to obtain written permission from the copyright owner prior to submission. More information on requesting permission to reproduce work(s) under copyright.

\section{Disclosure statement}

Please include a disclosure of interest statement, using the subheading "Disclosure of interest." If you have no interests to declare, please state this (suggested wording: The authors report no conflicts of interest). For all NIH/Wellcome-funded papers, the grant number(s) must be included in the disclosure of interest statement. Read more on declaring conflicts of interest.

\section{Clinical Trials Registry}

In order to be published in a Taylor \& Francis journal, all clinical trials must have been registered in a public repository at the beginning of the research process (prior to patient enrolment). Trial registration numbers should be included in the abstract, with full details in the methods section. The registry should be publicly accessible (at no charge), open to all prospective registrants, and managed by a not-for-profit organization. For a list of registries that meet these requirements, please visit the WHO International Clinical Trials Registry Platform (ICTRP). The registration of all clinical trials facilitates the sharing of information among clinicians, researchers, and patients, enhances public confidence in research, and is in accordance with the ICMJE guidelines.

\section{Complying with ethics of experimentation}

Please ensure that all research reported in submitted papers has been conducted in an ethical and responsible manner, and is in full compliance with all relevant codes of experimentation and legislation. All papers which report in vivo experiments or clinical trials on humans or animals must include a written statement in the Methods section. This should explain that all work was conducted with the formal approval of the local human subject or animal care committees (institutional and national), and that clinical trials have been registered as legislation requires. Authors who do not have formal ethics review committees 
should include a statement that their study follows the principles of the Declaration of Helsinki.

Consent

All authors are required to follow the ICMJE requirements on privacy and informed consent from patients and study participants. Please confirm that any patient, service user, or participant (or that person's parent or legal guardian) in any research, experiment, or clinical trial described in your paper has given written consent to the inclusion of material pertaining to themselves, that they acknowledge that they cannot be identified via the paper; and that you have fully anonymized them. Where someone is deceased, please ensure you have written consent from the family or estate. Authors may use this Patient Consent Form, which should be completed, saved, and sent to the journal if requested.

Health and safety

Please confirm that all mandatory laboratory health and safety procedures have been complied with in the course of conducting any experimental work reported in your paper. Please ensure your paper contains all appropriate warnings on any hazards that may be involved in carrying out the experiments or procedures you have described, or that may be involved in instructions, materials, or formulae.

Please include all relevant safety precautions; and cite any accepted standard or code of practice. Authors working in animal science may find it useful to consult the International Association of Veterinary Editors' Consensus Author Guidelines on Animal Ethics and Welfareand Guidelines for the Treatment of Animals in Behavioural Research and Teaching. When a product has not yet been approved by an appropriate regulatory body for the use described in your paper, please specify this, or that the product is still investigational. 